\title{
Model-Based Scenario Planning to Inform Climate Change Adaptation in the Northern Great Plains-Final Report
}

Open-File Report 2017-1129 



\section{Model-Based Scenario Planning to Inform Climate Change Adaptation in the Northern Great Plains-Final Report}

By Amy J. Symstad, Brian W. Miller, Jonathan M. Friedman, Nicholas A.

Fisichelli, Andrea J. Ray, Erika Rowland, and Gregor W. Schuurman

Open-File Report 2017-1129 


\title{
U.S. Department of the Interior \\ RYAN K. ZINKE, Secretary
}

\section{U.S. Geological Survey William H. Werkheiser, Acting Director}

\author{
U.S. Geological Survey, Reston, Virginia: 2017
}

For more information on the USGS - the Federal source for science about the Earth, its natural and living resources, natural hazards, and the environment-visit https://www.usgs.gov or call 1-888-ASK-USGS.

For an overview of USGS information products, including maps, imagery, and publications, visit https://store.usgs.gov.

Any use of trade, firm, or product names is for descriptive purposes only and does not imply endorsement by the U.S. Government.

Although this information product, for the most part, is in the public domain, it also may contain copyrighted materials as noted in the text. Permission to reproduce copyrighted items must be secured from the copyright owner.

Suggested citation:

Symstad, A.J., Miller, B.W., Friedman, J.M., Fisichelli, N.A., Ray, A.J., Rowland, Erika, and Schuurman, G.W., 2017, Model-based scenario planning to inform climate change adaptation in the Northern Great Plains-Final report: U.S. Geological Survey Open-File Report 2017-1129, 22 p., https://doi.org/10.3133/ofr20171129.

ISSN 2331-1258 (online) 


\section{Acknowledgments}

This report meets the reporting requirements of the North Central Climate Science Center for finished projects. We are grateful to the management partners who generously contributed their time and expertise to this effort, especially Craig Hansen, Wendy Ross, Rick Peterson, Milt Haar, and Terri Harris. We also thank Jacqueline Ott and Sheel Bansal for reviewing an earlier draft of this report. This research was funded by the Department of the Interior, North Central Climate Science Center. 



\section{Contents}

Acknowledgments ............................................................................................................................

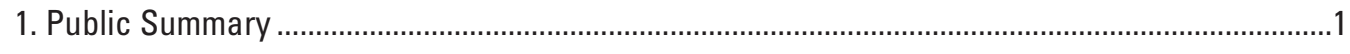

2. Project Summary

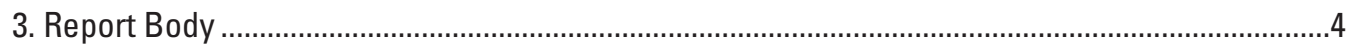

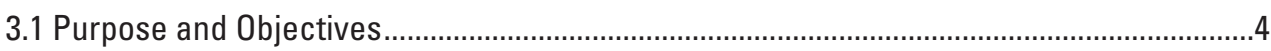

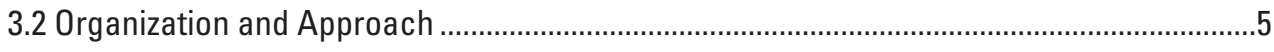

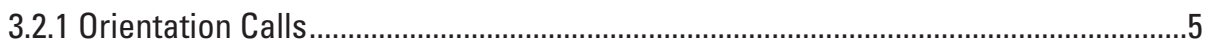

3.2.2 Regional Climate Summary Development ……………............................................

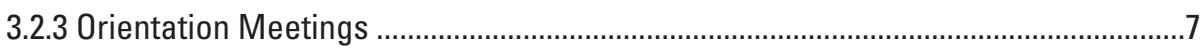

3.2.4 Early Quantitative Simulation Modeling ...................................................................

3.2.5 Local Climate Scenario Development .......................................................................

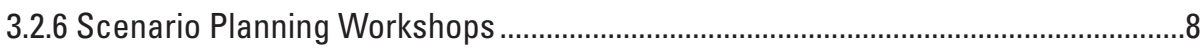

3.2.7 Refined Model and Simulations ..................................................................................

3.2.8 Quantitatively Informed Management Response Workshop .....................................8

3.2.9 Final Model and Simulations...........................................................................

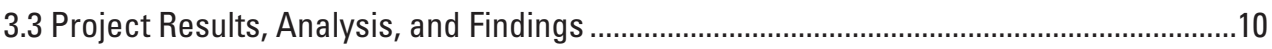

3.3.1 Regional Climate Summary ...................................................................................10

3.3.2 Central North Dakota Focal Area ......................................................................10

3.3.3 Southwest South Dakota Focal Area Scenario Planning Workshop ......................12

3.3.4 Quantitative Modeling of Grassland Vegetation Dynamics in the Southwest South Dakota Focal Area ....................................................................16

3.4 Conclusions and Recommendations ......................................................................18

3.4.1 Incorporating More Quantitative Methods into NPS Scenario

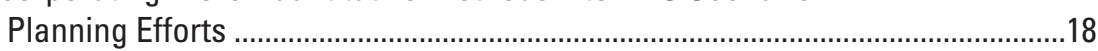

3.4.2 Things We May Have Done Differently and Recommended Next Steps ...............20

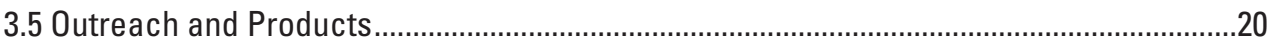

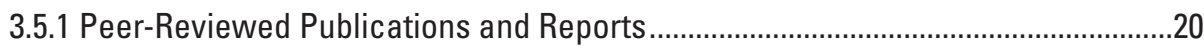

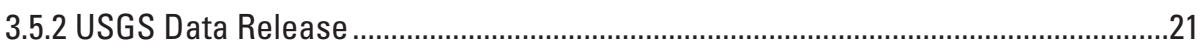

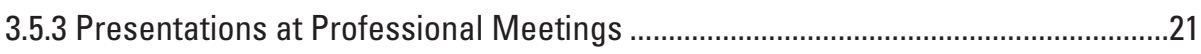

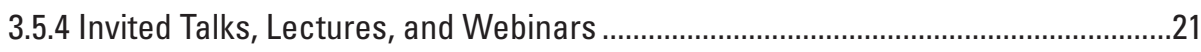

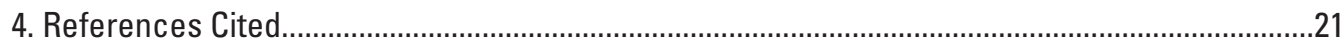

\section{Figures}

1. Map showing the study region and focal areas covered by this project ..........................2

2. Flowchart showing project organization and approach .................................................

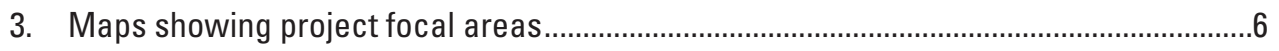

4. Graphs showing differences in key climate metrics between southwest South Dakota focal area scenarios and their historical average, and between five single years and the historical average for the Interior, South Dakota, weather station ..........14

5. Graphs showing simulated net primary production for each management jurisdiction under two climate scenarios and four management alternatives 
6. Graphs showing simulated live biomass for each management jurisdiction under two climate scenarios and four management alternatives

7. Graphs showing example of how climate and management interact over the long term

\section{Tables}

1. Brief descriptions of four simulated management alternatives for each management jurisdiction in the simulation model area delineated for the southwestern South Dakota focal area in figure 3.

2. Tabular representation of climate scenarios used for central North Dakota focal area

3. Workgroup assessment of the achievability of existing goals compared to needed revisions by 2050 for five resources.

\section{Conversion Factors}

International System of Units to U.S. customary units

\begin{tabular}{lcl}
\hline & Multiply & \multicolumn{1}{c}{ By obtain } \\
\hline & Length & \\
\hline millimeter $(\mathrm{mm})$ & 0.03937 & inch (in.) \\
\hline \multicolumn{3}{c}{ Area } \\
\hline hectare (ha) & 2.471 & acre \\
hectare (ha) & 0.003861 & square mile $\left(\mathrm{mi}^{2}\right)$ \\
\hline \multicolumn{3}{c}{ Mass } \\
\hline kilogram $(\mathrm{kg})$ & 2.205 & pound avoirdupois $(\mathrm{lb})$ \\
\hline & Application rate & \\
\hline kilograms per hectare per year $([\mathrm{kg} / \mathrm{ha}] / \mathrm{yr})$ & 0.8921 & pounds per acre per year $([\mathrm{lb} / \mathrm{acre}] / \mathrm{yr})$ \\
\hline & Flow rate & \\
\hline cubic meter per second $\left(\mathrm{m}^{3} / \mathrm{s}\right)$ & 15,850 & gallon per minute $($ gal $/ \mathrm{min})$ \\
\hline
\end{tabular}

Temperature in degrees Celsius $\left({ }^{\circ} \mathrm{C}\right)$ may be converted to degrees Fahrenheit $\left({ }^{\circ} \mathrm{F}\right)$ as follows: ${ }^{\circ} \mathrm{F}=\left(1.8 \times{ }^{\circ} \mathrm{C}\right)+32$.

\section{Datum}

Horizontal coordinate information is referenced to the North American Datum of 1983 (NAD 83). 


\section{Abbreviations}

$\begin{array}{ll}\text { CMIP3 } & \text { Coupled Model Intercomparison Project, Phase } 3 \\ \text { CMIP5 } & \text { Coupled Model Intercomparison Project, Phase } 5 \\ \text { NC CSC } & \text { North Central Climate Science Center } \\ \text { NEPA } & \text { National Environmental Policy Act } \\ \text { NPS } & \text { National Park Service } \\ \text { SWE } & \text { snow water equivalent } \\ \text { USGS } & \text { U.S. Geological Survey } \\ \text { VIC } & \text { variable infiltration capacity }\end{array}$





\title{
Model-Based Scenario Planning to Inform Climate Change Adaptation in the Northern Great Plains-Final Report
}

\author{
By Amy J. Symstad', Brian W. Miller', Jonathan M. Friedman', Nicholas A. Fisichelli2,3, Andrea J. Ray4, \\ Erika Rowland ${ }^{5,6}$, and Gregor W. Schuurman ${ }^{2}$
}

\section{Public Summary}

We worked with managers in two focal areas to plan for the uncertain future by integrating quantitative climate change scenarios and simulation modeling into scenario planning exercises.

In our central North Dakota focal area, centered on Knife River Indian Villages National Historic Site, managers are concerned about how changes in flood severity and growing conditions for native and invasive plants may affect archaeological resources and cultural landscapes associated with the Knife and Missouri Rivers. Climate projections and hydrological modeling based on those projections indicate plausible changes in spring and summer soil moisture ranging from a 7 percent decrease to a 13 percent increase and maximum winter snowpack (important for spring flooding) changes ranging from a 13 percent decrease to a 47 percent increase. Facilitated discussions among managers and scientists exploring the implications of these different climate scenarios for resource management revealed potential conflicts between protecting archeological sites and fostering riparian cottonwood forests. The discussions also indicated the need to prioritize archeological sites for excavation or protection and culturally important plant species for intensive management attention.

In our southwestern South Dakota focal area, centered on Badlands National Park, managers are concerned about how changing climate will affect vegetation production, wildlife populations, and erosion of fossils, archeological artifacts, and roads. Climate scenarios explored by managers and scientists in this focal area ranged from a 13 percent decrease to a 33 percent increase in spring precipitation, which is critical to plant growth in the northern Great Plains region, and

\footnotetext{
${ }^{1}$ U.S. Geological Survey.

${ }^{2}$ National Park Service.

${ }^{3}$ Schoodic Institute at Acadia National Park (current)

${ }^{4}$ National Oceanic and Atmospheric Administration.

${ }^{5}$ Wildlife Conservation Society.

${ }^{6}$ Upper Saco Valley Land Trust (current).
}

a slight decrease to a near doubling of intense rain events. Facilitated discussions in this focal area concluded that greater effort should be put into preparing for emergency protection, excavation, and preservation of exposed fossils or artifacts and revealed substantial opportunities for different agencies to learn from each other and cooperate on common management goals. Follow up quantitative simulation modeling of grassland dynamics helped quantify the degree of change expected in vegetation production under the wide range of climate scenarios and suggested that (a) low grazing rates could be adversely affecting vegetation composition in the national park and (b) understanding of the management practices needed to maintain desired vegetation conditions is incomplete.

\section{Project Summary}

Resource managers are tasked with managing complex systems with inherent uncertainty around how those systems might change with time and respond to management actions and a changing climate. Scenario planning (often implemented as a qualitative, participatory exercise for exploring multiple possible futures) is a valuable tool for addressing uncertainty. At the same time, quantitative information on projected climate changes and their impacts is rapidly growing and evolving, but this information is often not at a scale or in a form that is usable for resource managers. This project sought to pilot a process for combining qualitative and quantitative approaches in a way that would create usable information for resource managers in the northern Great Plains. In particular, project objectives were to

1. generate a climate summary (figures, tables, and narratives describing possible climate futures) for the northern Great Plains region delineated in figure 1;

2. derive local climate scenarios for two focal areas, southwestern South Dakota and central North Dakota;

3. formulate local climate-resource management scenarios to address priority resource management issues affected by climate change in each focal area; 


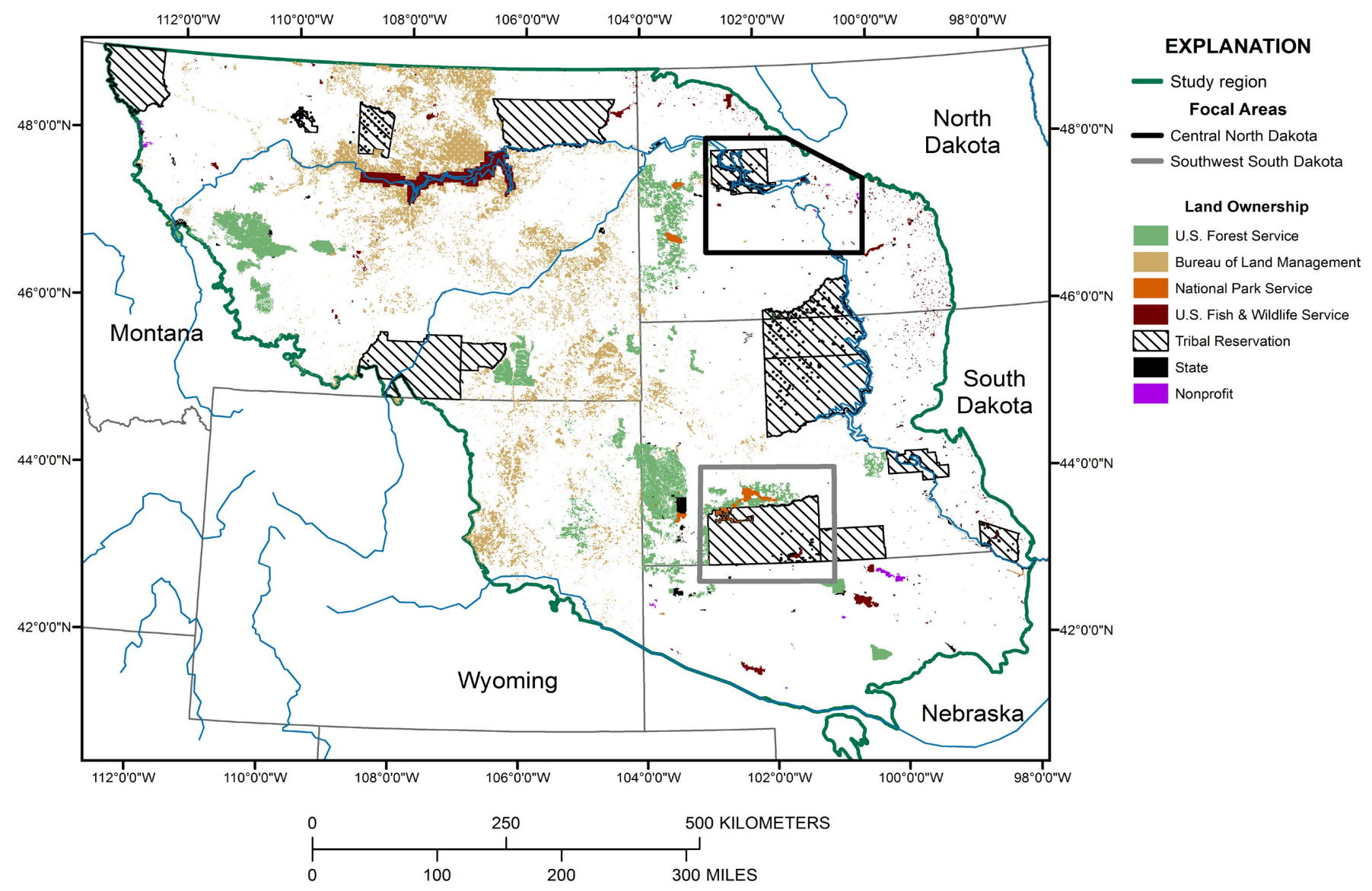

Figure 1. The study region (northern Great Plains) and focal areas covered by this project.

4. formulate and use quantitative models to simulate resource responses in quantitative climate-resource management scenarios in each focal area; and

5. work with stakeholders in each of the focal areas throughout the process.

To do so, we included stakeholders (managers of natural and cultural resources on public and Tribal land in our focal areas) throughout the process, beginning with orientation calls and meetings that identified the key management partners and resource management issues. These topics defined the scope and emphasis of our three project tasks - climate scenario development, participatory scenario planning, and quantitative simulation modeling - each with multiple interacting components.

For the regional climate summary, we compiled information from published reports to describe climatic trends over the last half century and the range of plausible futures for the northern Great Plains. We derived more detailed local climate scenarios, which focused on climate variables most relevant to resource management issues, for each of the focal areas. Local climate summaries were based on downscaled climate projections (Reclamation, 2013). These local climate scenarios served as the framework for focal area scenario planning workshops. The primary objectives of the workshops were to help local resource managers and scientists understand ongoing and future climate change and how to use scenario planning to make management and planning decisions based on assessments of critical future uncertainties. The scenario planning workshops were supplemented with quantitative information regarding resource response to climate change, which were tailored to each of the focal areas. Flooding effects on archeological sites and riparian vegetation were a priority in central North Dakota; therefore, for this focal area, we analyzed changes in flow for the Knife River using output from the Bureau of Reclamation Variable Infiltration Capacity (VIC) hydrology model. For the South Dakota study site, we coproduced a spatially explicit, state-and-transition simulation of vegetation dynamics to explore vegetation responses (production, biomass, and community composition) to alternative 
management practices (fire, invasive species inventory and treatment, and grazing) in the four different climate scenarios that were described in the local climate scenarios. Model coproduction entailed iteration with local subject-matter experts and resource managers, including

- modifications to conceptual models (through phone and email),

- feedback on prototype model and scenarios (at scenario planning workshop),

- preparation for expert elicitation (webinar),

- expert elicitation (email),

- sharing of model results (webinar),

- interpretation of initial results (second webinar),

- feedback on model specification and scenarios (second workshop), and

- feedback on peer-reviewed manuscript (email).

Project main findings and results were as follows:

- Climate projections for the northern Great Plains consistently indicate continued warming, but projections are not consistent on the direction and magnitude of change in annual precipitation.

- Stakeholder questions and concerns drove the development of the four local climate scenarios for each focal area, which were summarized in multiple formats and included comparisons to memorable climate events.

- Scenario planning for a wide range of resources facilitated openminded thinking about a set of divergent and challenging, yet relevant and plausible, climate scenarios and management alternatives. The scenario planning workshops informed a review of the Knife River Indian Villages National Historic Site Archaeological Management Plan (which was in the final stages of the National Environmental Policy Act [NEPA] process), and the project team provided advice on means for streamlining and strengthening the park's riverbank erosion monitoring protocol. For the South Dakota site, the scenario planning workshop started discussions around potential management responses to climate changes and identified the climate and management scenarios that were explored in the ecological simulations.

- In the process of developing quantitative descriptions of Knife River flows, we discovered that the VIC output poorly simulated historical winter peak flows, and the snow water equivalent (SWE) output from the version of VIC used for CMIP5 projections poorly simulated historical data compared to the CMIP3 simulations. The discrepancy in SWE between CMIP3 and CMIP5 extends over most of North Dakota, South Dakota, Nebraska, Montana, and Wyoming. We believe that this issue is important for other climate projects using this output at local scales.

- The simulation modeling effort for the South Dakota focal area led to the discovery of counterintuitive and surprising findings and resulted in a more tractable set of possible futures to plan for. In particular, the effort provided insights valuable to managers and scientists regarding (a) biomass availability for grazers during dry periods, (b) tradeoffs between biomass security and vegetation composition, (c) the contribution to important ecosystem components of climate relative to management, and (d) the state of knowledge regarding the response of these grasslands to various management practices.

The products of this project include

- two National Park Service (NPS) reports,

- three peer-reviewed journal publications (one published, one in press, and one in preparation as of November 7, 2017),

- six presentations at professional meetings, and

- four invited talks, lectures, and webinars.

This project provided the knowledge and experience to build a framework for making scenario planning more quantitative and usable for resource managers (Symstad and others, 2017). Based on this experience and other findings mentioned throughout this report, we recommend the following actions:

- In future efforts like this, allow for additional time to engage managers in the process and to expand the group of local experts by engaging local resource users who could draw on traditional ecological knowledge and practice-based knowledge to assist with model coproduction and improve model relevance to local communities.

- Build upon the work we started to produce a flexible yet repeatable method for selecting and producing quantitative climate scenarios.

- Determine a method for deciding where greater quantification of the scenario planning process is most beneficial and cost effective.

- Consult with project stakeholders to determine the most useful form of the voluminous and multifaceted modeling output so that the results will be used in future planning efforts. 


\section{Report Body}

\subsection{Purpose and Objectives}

The great variety of resource management challenges in a changing climate has stimulated calls to make climate science more "usable" or "actionable." Our purpose was to do this by combining climate projections, scenario planning, and simulation modeling through an iterative, participatory process.

Climate change is expressed in both regional patterns of shifting climatic conditions and local impacts to resources. Resource management under climate change is challenging because impacts are widespread and cannot be precisely predicted. The National Park Service (NPS) and other organizations use participatory scenario planning workshops to explore plausible futures and implications for management. This process aims to empower decision makers to take action and manage under uncertainty. Past NPS efforts have largely treated resource responses qualitatively and focused on raising staff climate literacy. New demands from managers include quantitative modeling approaches to assess specific management needs, but these approaches require substantial time and expertise beyond the capacity of most managers. Our project was developed to address these demands by using two case studies to explore the possibilities for making the NPS scenario planning process more quantitative.

Our project proposal stated that our overarching goal was to develop a streamlined and standardized process for scaling climate change adaptation by creating regional climate summaries and applying them to local scenario planning, according to the following three objectives:

1. Generate three to five climate summaries (figures, tables, and narratives describing plausible climate futures) for a broad region, the northern Great Plains.

2. Derive local climate summaries and apply them to management-scale scenario planning efforts in two focal areas, southwestern South Dakota and central North Dakota.

3. Work with stakeholders in each of these focal areas to develop qualitative and quantitative climate-resource management scenarios ("scenarios") through an orientation phase followed by a scenario planning workshop and further meetings with key managers.

After initial conversations with project management partners and in the process of completing a project study plan, we refined our overarching goal and specific objectives to the following:

Goal: Explore the costs and benefits of incorporating more quantitative methods into NPS scenario planning efforts and, if warranted, develop a streamlined and standardized process for doing so.
1. Generate a climate summary (figures, tables, and narratives describing possible climate futures) for the northern Great Plains region delineated in figure 1.

2. Derive local climate scenarios for two focal areas, southwestern South Dakota and central North Dakota.

3. Formulate local climate-resource management scenarios to address priority resource management issues affected by climate change in each focal area.

4. Formulate and use quantitative models to simulate resource responses in quantitative climate-resource management scenarios in each focal area.

5. Work with stakeholders in each of the focal areas throughout the process.

In our proposal, we envisioned generating three to five regional climate summaries, each derived from a single global climate model projection, and together spanning a range of plausible, challenging, relevant, and divergent conditions for the northern Great Plains region as a whole. We expected to "scale down" these regional summaries to the local level by selecting pertinent information based on input from local managers on which aspects of climate they considered most important for their management concerns. These local summaries were to serve as the basis for a participatory scenario planning workshop focused on the local area, but initial discussions with land managers in the focal areas for our project made clear that this "top-down" approach was inappropriate. The approach would not provide the flexibility needed to address local management concerns because it was unlikely to capture a sufficient range of plausible futures for the large number of climate drivers important to a multitude of management issues in three to five projections preselected based on "typical" climate factors such as annual temperature and precipitation; therefore, we modified this objective to develop a single, regional climate summary that synthesized published descriptions of climate change projections for the northern Great Plains. We presented this summary at orientation meetings with land managers and used it as the basis for discussions used to determine the critical climate drivers for each focal area.

We achieved the remaining four objectives as planned using the approaches described below in section 3.2 and producing the results described in section 3.3. Detailed methods and results are provided in two project reports (Fisichelli and others, 2016a, b) and one manuscript in press at the time of this publication (Miller and others, in press). In addition, our experience in developing the local climate scenarios prompted us to begin work on an additional objective, developing a set of R scripts to make the process of developing local climate summaries consistent and streamlined. After making some progress on this objective, we halted work on it to avoid duplicating similar efforts by the North Central Climate Science Center (NC CSC) and pending further guidance from the NPS Climate Change Response Program, who was the primary intended user of the product. 


\subsection{Organization and Approach}

Our project was organized into three interacting tasksclimate scenario development, participatory scenario planning, and quantitative simulation modeling - each with multiple components. We completed these tasks according to the process outlined in figure 2 for the two focal areas shown in figure 3.

\subsubsection{Orientation Calls}

As our fifth objective states, we included stakeholders-managers of natural and cultural resources on public and Tribal land in our focal areas - throughout the process. We held orientation calls with the primary stakeholders - staff of the NPS units at the center of each focal area-in April 2015 to (a) identify additional stakeholders to invite into the project, (b) introduce stakeholders and project staff to each other, (c) exchange information regarding management issues, planning timeframes, and available relevant science, and (d) compile a preliminary list of resource management issues of concern.

\subsubsection{Regional Climate Summary Development}

Our project climate specialist compiled information from published reports (e.g., Kunkel and others, 2013; Sun and others, 2015) into a presentation describing, for northern Great

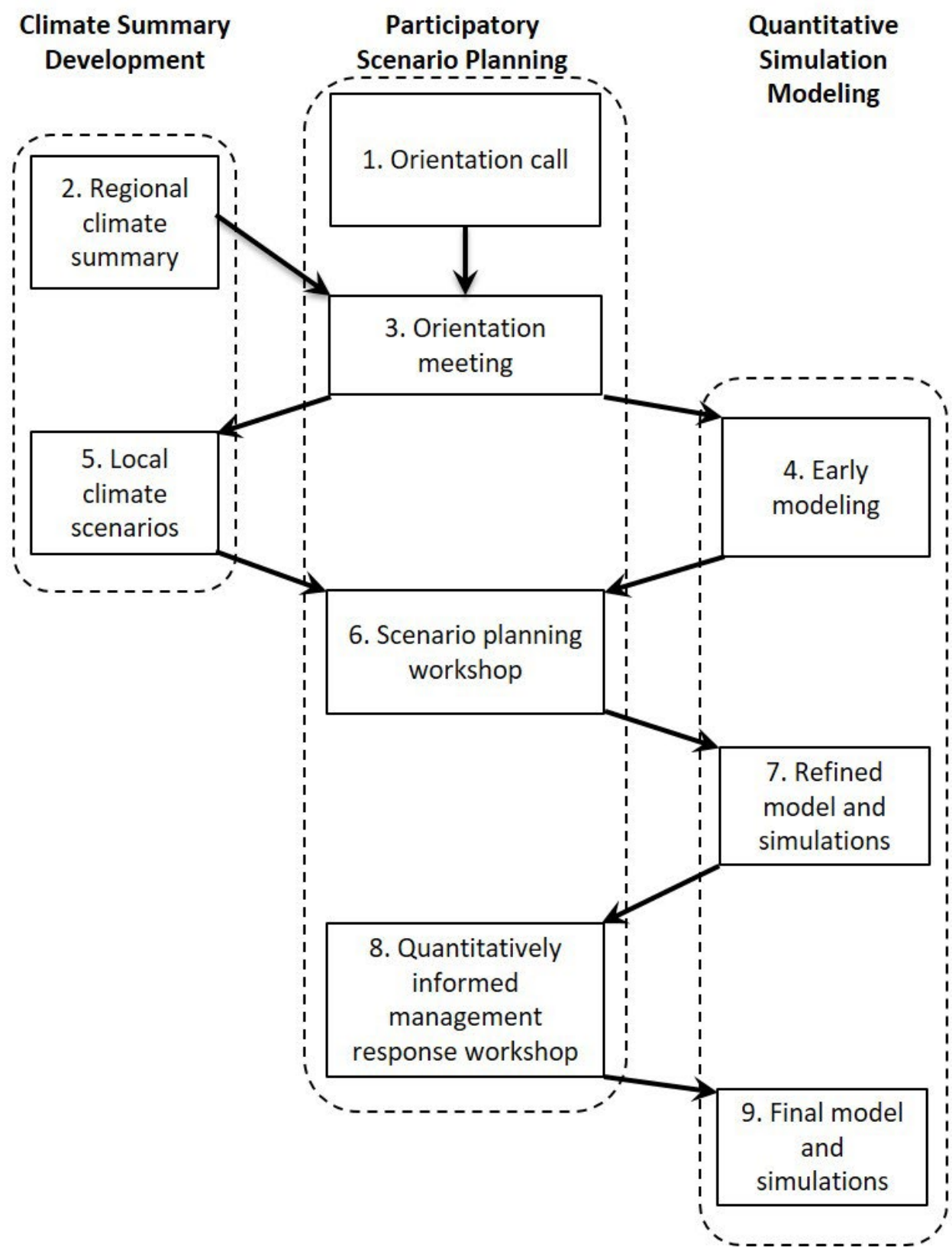

Figure 2. Project organization and approach. 

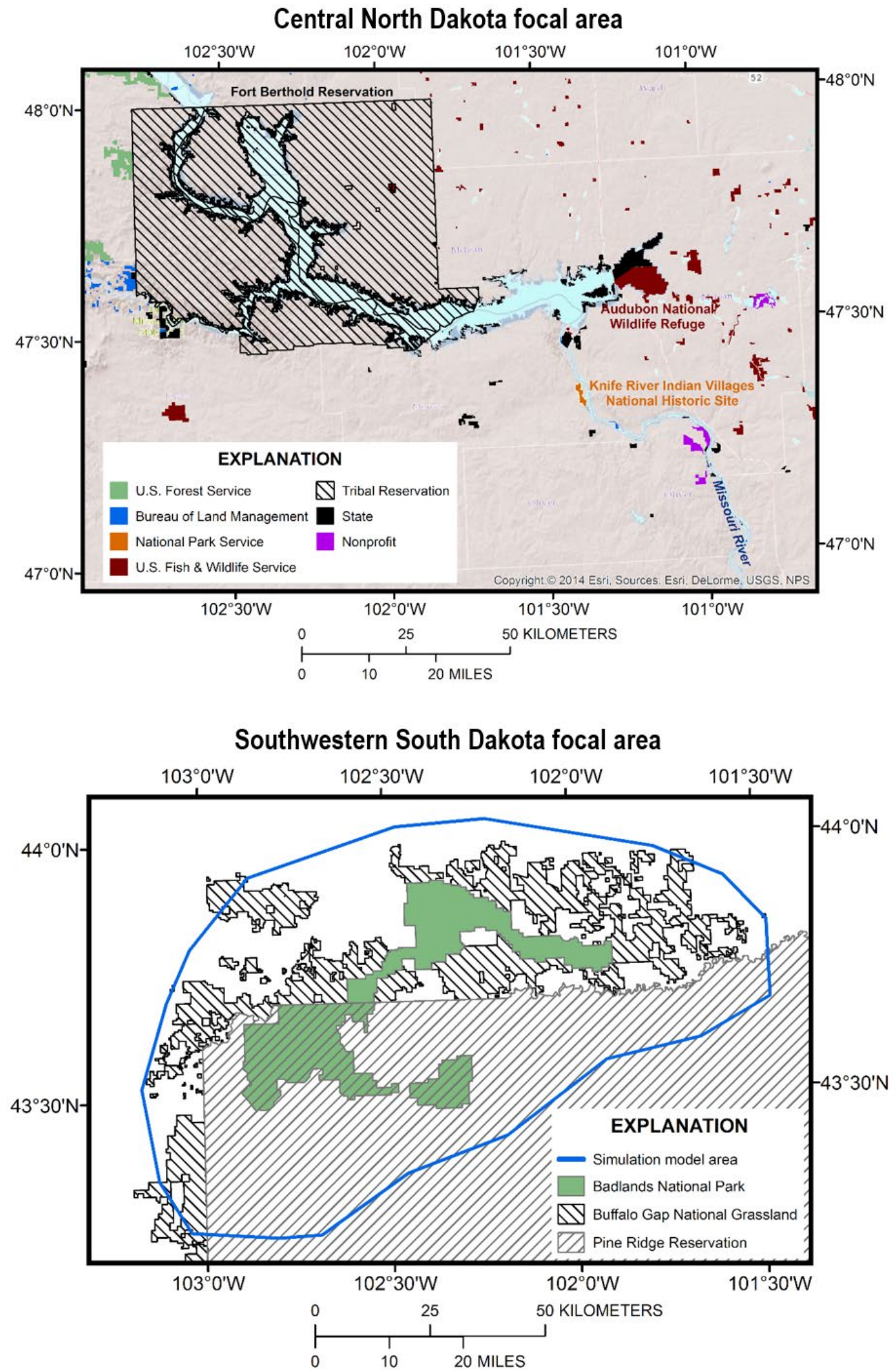

Figure 3. Project focal areas. 
Plains, climatic trends of the past half-century and the range of plausible futures projected in both CMIP3 and CMIP5 climate modeling efforts. As described above, we realized that this overview, rather than a specific set of regional climate projections, was the appropriate tool for stimulating stakeholder discussion regarding the aspects of climate change most important to their resource management concerns.

\subsubsection{Orientation Meetings}

Orientation meetings were held at stakeholder-chosen locations in central North Dakota and southwestern South Dakota in August 2015. These meetings built relationships started in the orientation calls by introducing, in person, project scientists and a greater field of stakeholders than in the April calls. Other objectives of these 1-day meetings were to (a) review project goals, methods, and timeline, including setting a tentative date for each focal area's scenario planning workshop; (b) confirm the focal issues that would be explored in the workshop; (c) identify critical and uncertain climate drivers of high priority management issues; (d) identify additional information sources; and (e) identify additional stakeholders to invite to the workshop.

\subsubsection{Early Quantitative Simulation Modeling}

Discussions during the orientation calls and meetings highlighted the need for different types of quantitative information regarding resource responses to climate change in each of the focal areas. Although upland prairie communities were a priority in both focal areas, flooding effects on archeological sites and riparian vegetation were a priority in central North Dakota. To address this concern, our project hydrology specialist analyzed changes in magnitude of the annual peak flow in winter (January-April) and summer (May-October) for the Knife River using output from an existing hydrological model, the Bureau of Reclamation VIC hydrology model (data from http://gdo-dcp.ucllnl.org/downscaled_cmip_projections; Reclamation, 2013). Details of this analysis are in appendix 1 of Fisichelli and others (2016a). Results of this analysis were used in our selection of local climate scenarios for the central North Dakota focal area.

In the southwestern South Dakota focal area, no existing models were sufficient to address the questions about erosion and vegetation composition discussed in the orientation meetings. Given the limited time to complete the project, the expertise of the project scientists, and the availability of information needed to build a model to address these questions, we chose to build a model to explore vegetation responses to alternative management practices in different climate scenarios, but we did not build a model to explore erosion behavior in these scenarios. We built a spatially explicit, state-and-transition simulation model, in the ST-Sim software package (version 3.0.24; Apex Resource Management Solutions, 2017), that simulated grassland net primary production, live biomass at the end of the growing season, and community composition. Composition was represented by state classes, which were based on plant community states and phases in Natural Resources Conservation Service ecological site descriptions for the model area. State classes were characterized by their dominant species, such as the desirable western wheatgrass/ needlegrass state and the undesirable cool-season exotic grass state. The model incorporated the effects of climate, fire, grazing, and invasive species on these ecosystem response variables. Model details are in Miller and others (in press). The complexity of the model needed to address vegetation responses precluded our being able to provide simulation results in time for the southwestern South Dakota scenario planning workshop. Instead, we presented the prototype model to a group of local managers and subject-matter experts through a webinar/conference call in early January 2016 and made a similar presentation at the end of the scenario planning workshop to all interested participants. We obtained valuable feedback from call and workshop participants. To more fully explore the model results and their management implications, we organized a second workshop for later that spring (described in section 3.2.8).

\subsubsection{Local Climate Scenario Development}

Using the results of the discussions during the orientation meetings, we developed four midterm (2020-50) climate scenarios for each focal area to serve as the framework for the focal area's scenario planning workshop. Scenarios useful for such workshops represented alternative climatic conditions that could play out in the coming decades and met four basic criteria: plausible, challenging, relevant, and divergent (National Park Service, 2013). The scenarios were intended to specifically challenge manager thinking on implications for the resources selected as priorities in the orientation meetings; thus, the climate scenarios for central North Dakota explicitly considered climatic uncertainties expected to affect river flooding and growing season soil moisture because of their importance to erosion of archaeological sites and vegetation composition, respectively. For southwest South Dakota, the climate scenarios focused on heavy precipitation events, which affect paleontological, archaeological, and infrastructure resources, and on early growing season precipitation and the timing of late-spring freezes, which affect vegetation productivity and therefore forage for wildlife.

We produced quantitative, local climate summaries for each of the four climate scenarios at each site using data downloaded from the "Downscaled CMIP3 and CMIP5 Climate and Hydrology Projections" website (https://gdo-dcp.ucllnl.org/downscaled_cmip_projections). After calculating a variety of climate metrics of general interest (for example, monthly temperature and precipitation) and of interest because of the specific resource concerns at each site (for example, peak snowpack and summer peak flow for central North Dakota, and April-June precipitation and frequency of heavy precipitation events for southwest South 
Dakota) for 36 projections, we used these metrics to select 4 projections that met the basic criteria for scenarios listed above. Before sharing the scenario descriptions with workshop participants, we vetted them with local meteorologists and NC CSC Foundational Science Area climatologists Imtiaz Rangwala and Joe Barsugli. Scenario descriptions shared with workshop participants consisted of tables, graphs, and text and are included in workshop reports (Fisichelli and others, 2016a, b).

\subsubsection{Scenario Planning Workshops}

We used the local climate summaries as the basis for two-day scenario planning workshops for each of the focal regions (November 12-13, 2015, for central North Dakota and January 20-21, 2016, for southwest South Dakota). The primary objectives of the workshops were to help local resource managers and scientists understand ongoing and future climate change and how to use scenario planning to make management and planning decisions based on assessments of critical future uncertainties. The workshops involved a broad group of decision-makers and scientists, and included a mixture of science and adaptation presentations from project team members and local experts; breakout group exercises; and group discussions of scenarios, their resource management implications, and potential management responses.

\subsubsection{Refined Model and Simulations}

It became clear soon after the central North Dakota workshop that the quantitative modeling of flood behavior used in the workshop was sufficient for the primary stakeholders to incorporate the implications from workshop discussions into their immediate management planning, which focused on archeological resources. A different type of quantitative modeling would support planning regarding cultural landscapes and the plant communities that comprise them. Because primary stakeholder objectives regarding these resources have not yet been developed, we felt that, given the timeframe and funding for this project, model development would have been premature; therefore, we did no further modeling for this focal area.

In contrast, questions that arose during discussions regarding bison and vegetation management at the southwestern South Dakota workshop guided us in refining the prototype vegetation model and determining relevant climateresource management scenarios to simulate with the refined model. After the workshop, we updated and parameterized the model using information on prescribed fire priorities and effectiveness, Canada thistle treatment effectiveness, exotic invasion vulnerability, and grazing (and absence of grazing) effects from expert elicitation, and we used empirical relations in the published literature to model the effect of weather on vegetation productivity. We then ran the model using all combinations of the four climate scenarios used in the January workshop and four different management alternatives for each of three management areas. These management areas represented the different management approaches in Buffalo Gap National Grassland (hereafter referred to as "the Grassland"), Badlands National Park ("the Park"), and Tribal or private lands on the Pine Ridge Reservation ("the Reservation"). These management alternatives are briefly described in table 1, and Miller and others (in press) provides a detailed description of the model and management alternatives.

Although this approach of constructing distinct storylines for a management alternative is consistent with the scenario planning approach we desired in this project, it does complicate understanding of the effects of individual management actions (for example, increasing fire frequency) in isolation from other adjustments to management. To address this shortcoming, we completed a sensitivity analysis of four parameters-climate effect on grazing-induced state changes, climate effect on Canada thistle establishment, grazing consumption level, and prescribed fire area-for a part of the model area.

\subsubsection{Quantitatively Informed Management Response Workshop}

Instead of a second workshop for the central North Dakota focal area, our project team wrapped up our work with this group by reviewing the Knife River Indian Villages National Historic Site Archeological Management Plan (which was in the final stages of the NEPA process), and by providing advice on means for streamlining and strengthening the park's riverbank erosion monitoring protocol.

In the southwest South Dakota focal area, we presented the results of our simulation modeling using the refined vegetation model to a subset of the first workshop's participantsthose focused on vegetation and wildlife - in a webinar in early May 2016. We held a 1-day workshop a week later to discuss those results and their implications for management. This workshop was largely unstructured to allow ample time for interactive discussion, which covered not only results and implications but also suggestions for final refinements to the model.

\subsubsection{Final Model and Simulations}

The open discussion among managers, climate change response specialists, scientists, and modeling specialists in the May workshop in South Dakota suggested more refinements to the model (for example, dynamic stocking rates) and to the management alternatives simulated with the model. After completing these refinements, we ran a final set of simulations, which formed the basis for the primary science product of this project, the Miller and others manuscript now in revision for Ecosphere. Results were largely similar to those presented and discussed in the management response workshop and are provided in full in Miller and others (2017). Before submitting this manuscript to the journal, we sought input on its text from 
Table 1. Brief descriptions of four simulated management alternatives for each management jurisdiction in the simulation model area delineated for the southwestern South Dakota focal area in figure 3.

\begin{tabular}{|c|c|c|c|}
\hline \multirow{2}{*}{$\begin{array}{l}\text { Management } \\
\text { Component }\end{array}$} & \multicolumn{3}{|c|}{ Management Jurisdiction } \\
\hline & Buffalo Gap National Grassland & Badlands National Park & Pine Ridge Reservation \\
\hline \multicolumn{4}{|c|}{ “Current practice” management alternative } \\
\hline thistle inventory & $\begin{array}{l}33 \text { percent of simulated area invento- } \\
\text { ried each year. }\end{array}$ & $\begin{array}{l}3 \text { percent of simulated area invento- } \\
\text { ried each year. }\end{array}$ & $\begin{array}{l}1 \text { percent of simulated area invento- } \\
\text { ried each year. }\end{array}$ \\
\hline thistle treatment & $\begin{array}{l}33 \text { percent of detected thistle chemi- } \\
\text { cally treated each year, priority on } \\
\text { large patches. }\end{array}$ & $\begin{array}{l}0.2 \text { percent of simulated area chemi- } \\
\text { cally treated each year, priority on } \\
\text { large patches. }\end{array}$ & $\begin{array}{l}\text { All detected thistle chemically treated } \\
\text { each year. }\end{array}$ \\
\hline grazing & $\begin{array}{l}\text { Same as "current practice," except } \\
\text { consumption can increase and } \\
\text { decrease. }\end{array}$ & $\begin{array}{l}\text { Year-round grazing in expanded bison } \\
\text { range, } 8 \text { percent consumption rate. }\end{array}$ & Same as "current practice." \\
\hline fire & $\begin{array}{l}7 \text { percent of simulated area, half in } \\
\text { spring, half in fall. }\end{array}$ & $\begin{array}{l}10 \text { percent of simulated area, more in } \\
\text { spring than fall. }\end{array}$ & $\begin{array}{l}10 \text { percent of simulated area spread } \\
\text { across spring, summer, and fall. }\end{array}$ \\
\hline thistle inventory & Same as "current practice." & $\begin{array}{l}20 \text { percent of simulated area invento- } \\
\text { ried each year. }\end{array}$ & $\begin{array}{l}20 \text { percent of simulated area invento- } \\
\text { ried each year. }\end{array}$ \\
\hline thistle treatment & $\begin{array}{l}33 \text { percent of detected thistle chemi- } \\
\text { cally treated, priority on small } \\
\text { patches. }\end{array}$ & All detected thistle chemically treated. & $\begin{array}{l}\text { All detected thistle treated with } \\
\text { biocontrol. }\end{array}$ \\
\hline \multicolumn{4}{|c|}{ "Planning for good conditions" management alternative } \\
\hline \multicolumn{4}{|c|}{ “Planning for poor conditions" management alternative } \\
\hline grazing & $\begin{array}{l}\text { Consumption } 57 \text { percent of "current } \\
\text { practice." }\end{array}$ & $\begin{array}{l}\text { Consumption } 67 \text { percent of "current } \\
\text { practice." }\end{array}$ & $\begin{array}{l}\text { Consumption } 67 \text { percent of "current } \\
\text { practice." }\end{array}$ \\
\hline fire & Same as "current practice." & $\begin{array}{l}0.8 \text { percent and } 0.9 \text { percent of simu- } \\
\text { lated area in spring and summer, } \\
\text { respectively. }\end{array}$ & $\begin{array}{l}0.3 \text { percent of simulated area in sum- } \\
\text { mer. }\end{array}$ \\
\hline thistle inventory & Same as "current practice." & Same as "current practice." & Same as "current practice." \\
\hline thistle treatment & Same as "current practice." & Same as "current practice." & Same as "presently preferred." \\
\hline
\end{tabular}


the two managers who had been most involved with the work, emphasizing our wish that they thoroughly review our interpretation of management implications discussed at the workshop. We incorporated their input into the manuscript submitted to the journal. Part of an extension to this project granted by the NC CSC will distill the voluminous and multifaceted results of the modeling into a management-relevant resource brief for easy use by project participants and their supervisors.

\subsection{Project Results, Analysis, and Findings}

The summaries of project results below draw strongly from our two scenario planning workshop reports (Fisichelli and others, 2016a, b) and our paper in Ecosphere (Miller and others, in press). We encourage the reader to consult these documents for greater detail.

\subsubsection{Regional Climate Summary}

Future climate projections for the northern Great Plains consistently indicate continued warming of $2.2-2.7^{\circ} \mathrm{C}$. Projections are much less consistent on the direction and magnitude of change in annual precipitation but generally indicate increasing precipitation in the northeastern two-thirds of the region and no change or a slight reduction in precipitation in the southwestern third (Kunkel and others, 2013).

\subsubsection{Central North Dakota Focal Area}

Participants in the orientation meeting for the central North Dakota focal area asked questions such as, "Although conditions are warming, will the effective growing season length expand or will it contract because of moisture limitation?" and "Will river flooding become more or less intense in early spring when snow and river ice melts, and will there be an increase in summer flooding related to heavy precipitation events?" They also identified three related focal topics and concerns with broad appeal across agencies: archeological sites and cultural landscapes, riparian ecosystems, and upland grasslands. As described above, these questions and concerns drove our selection of four climate projections as the basis of the local climate scenarios for the focal area's scenario planning workshop.

In the process of developing quantitative descriptions of peak flow for the Knife River for these scenarios, we met some challenges in using the VIC output provided on the Bureau of Reclamation website for this purpose. Specifically, in backcasting mode, the VIC output matched historical flows (1950-99) in summer, but it had no skill in predicting winter peak flows in this small drainage basin. This result was not surprising given the notorious difficulty in modeling snowmelt runoff and ice jams, and the focus of the VIC modeling effort on matching flow in large drainage basins like the Missouri River, not in small drainage basins like the Knife River. Annual peak SWE predicted by the VIC version used for CMIP3 projections proved to be a reasonable surrogate, matching both winter peak flows and measured snow depth in Bismarck, N. Dak. We were surprised, however, to see that SWE output from the version of VIC used for CMIP5 projections poorly simulated historical data compared to the CMIP3 simulations. Under CMIP5, snow accumulations were far too low in comparison to snow measurements in Bismarck and flow measurements in the Knife River. Given this issue, we only used CMIP3 projections as candidates for scenarios in our scenario planning workshop. In follow-up work, two of our team members explored the geographic extent of this problem with VIC hydrology output under CMIP5 and determined that, at the least, the discrepancy in SWE between CMIP3 and CMIP5 extends over most of North Dakota, South Dakota, Nebraska, Montana, and Wyoming. We believe that this issue is important for other climate projects using this output at the local scales, in that, because the VIC model was calibrated to match hydrology of big rivers at a continental scale, it is not as reliable for smaller rivers.

The four climate scenarios for this focal area, each of which was given a descriptive, memorable name, are summarized in table 2 . The "warm with wet summer" scenario was chosen to represent conditions similar to those of the most recent decade, although continued warming was inescapable. The "hot summer, soggy spring" and "hot flood seesaw" scenarios both represented conditions of more flooding but with different emphases on spring and summer flooding, degree of increased soil moisture conditions, and consistency from year to year (the "hot flood seesaw" scenario being highly variable). The "severe sustained drought" scenario was selected to represent the opposite type of challenge - a decline in precipitation that, although contrary to the average of projections for the area, is still plausible. An important component of creating the climate scenarios was relating them to memorable climatic events, which we did in this focal area by noting how frequently each scenario experienced winter and summer flood events comparable to exceptional floods in the 1990s (last two rows in table 2).

During the scenario planning workshop, workshop participants discussed then described their vision of how an individual climate scenario would affect the three focal issues identified during orientation, as well as local sociopolitical factors, facilities, and infrastructure. Only the "severe sustained drought" scenario envisioned a decrease in the loss of archeological sites to flooding, and two of the scenarios envisioned substantial increases in this loss. Recruitment of cottonwood trees along riparian areas, a concern because of flood control structures in the focal area, was seen to benefit from more flooding in two scenarios, stay the same (low) in one, and nearly cease in the driest scenario. Participants also envisioned higher plant productivity and greater success in prairie restorations in the wetter scenarios, but they also expressed great concern about invasive species, their ability to complete spring prescribed fires, and conversion of remaining grasslands to cropland in these scenarios. The drought scenario envisioned the opposite effects, plus an increase in 
Table 2. Tabular representation of climate scenarios used for central North Dakota focal area.

[Unless otherwise specified, each value is the difference between the 2020-49 average and the 1950-90 average of a climate metric. Details of how values were derived are in Fisichelli and others (2016a). SWE, snow water equivalent; W, winter; Sp, spring; Su, summer; Fa, fall. Temperature values are in ${ }^{\circ} \mathrm{C}$. Precipitation values are in millimeters.]

\begin{tabular}{|c|c|c|c|c|}
\hline \multirow[b]{2}{*}{ Climate Metric } & \multicolumn{4}{|c|}{ Scenario } \\
\hline & $\begin{array}{l}\text { Warm with } \\
\text { wet summer }\end{array}$ & $\begin{array}{l}\text { Hot summer, } \\
\text { soggy spring }\end{array}$ & $\begin{array}{l}\text { Hot flood } \\
\text { seesaw }\end{array}$ & $\begin{array}{l}\text { Severe sustained } \\
\text { drought }\end{array}$ \\
\hline Annual temperature & +0.9 & +1.8 & +1.7 & +2.3 \\
\hline Seasonal temperature & $\begin{array}{l}\text { W: }+1.2 \\
\text { Sp: }+0.6 \\
\text { Su: }+0.9 \\
\text { Fa: }+0.9\end{array}$ & $\begin{array}{l}\text { W: }+0.9 \\
\text { Sp: }+1.7 \\
\text { Su: }+2.8 \\
\text { Fa: }+1.9\end{array}$ & $\begin{array}{l}\text { W: }+2.3 \\
\text { Sp: }+2.6 \\
\text { Su: }+2.1 \\
\text { Fa: }+1.4\end{array}$ & $\begin{array}{l}\text { W: }+2.6 \\
\text { Sp: }+2.1 \\
\text { Su: }+2.4 \\
\text { Fa: }+2.1\end{array}$ \\
\hline Annual precipitation & $+10(+2 \%)$ & $+58(+12 \%)$ & $+89(+17 \%)$ & $-33(-8 \%)$ \\
\hline Seasonal precipitation & $\begin{array}{l}\mathrm{W}:+3(+7 \%) \\
\text { Sp: }+8(+7 \%) \\
\text { Su: }+10(+4 \%) \\
\text { Fa: }-10(-13 \%)\end{array}$ & $\begin{array}{l}\text { W: }+10(+26 \%) \\
\text { Sp: }+8(+6 \%) \\
\text { Su: }+18(+8 \%) \\
\text { Fa: }+23(+22 \%)\end{array}$ & $\begin{array}{l}\text { W: }+10(+22 \%) \\
\text { Sp: }+23(+17 \%) \\
\text { Su: }+36(+14 \%) \\
\text { Fa: }+23(+21 \%)\end{array}$ & $\begin{array}{c}\text { W: }+1(+4 \%) \\
\text { Sp: }+18(+13 \%) \\
\text { Su: }-38(-22 \%) \\
\text { Fa: }-15(-21 \%)\end{array}$ \\
\hline Growing season length & +20 days/year & +25 days/year & +25 days/year & +30 days/year \\
\hline Spring (March-May) soil moisture & $-2 \%$ & $+8 \%$ & $+13 \%$ & $-7 \%$ \\
\hline $\begin{array}{l}\text { Percent of years with spring soil moisture } \\
\text { lower than historical average }\end{array}$ & $43 \%$ & $47 \%$ & $33 \%$ & $73 \%$ \\
\hline Summer (June-August) soil moisture & $+2 \%$ & $+4 \%$ & $+11 \%$ & $-5 \%$ \\
\hline $\begin{array}{l}\text { Percent of years with summer soil mois- } \\
\text { ture lower than historical average }\end{array}$ & $53 \%$ & $53 \%$ & $40 \%$ & $73 \%$ \\
\hline Peak winter snow water equivalent (SWE) & $-9 \%$ & $+20 \%$ & $+47 \%$ & $-13 \%$ \\
\hline Summer peak flow & $+17 \%$ & $+78 \%$ & $+46 \%$ & $-11 \%$ \\
\hline Percent of years with snow like $1996-97^{a}$ & $0 \%$ & $10 \%$ & $7 \%$ & $0 \%$ \\
\hline $\begin{array}{l}\text { Percent of years with summer flooding } \\
\text { like } 1993^{\text {b }}\end{array}$ & $13 \%$ & $40 \%$ & $30 \%$ & $10 \%$ \\
\hline
\end{tabular}

${ }^{\text {aPercent }}$ of years with maximum SWE $\geq 61 \mathrm{~mm}$.

${ }^{b}$ Percent of years with summer peak daily mean flow $>127$ cubic meters per second.

wildfires. Although the drought scenario expected reduced costs for infrastructure repair and maintenance (because of less flood damage), it also envisioned stress on local economies because of decreased water for agriculture, energy generation, and recreational visitation.

These fleshed out scenarios served as the basis for the final discussions in the scenario planning workshop, which focused on examining the efficacy of a range of plausible management responses to changing climate for three focal concerns - cottonwood forests, archeological sites, and vegetation in cultural landscapes. These discussions were guided by a framework of three adaptation strategies: resist change, accommodate change, or direct change (Fisichelli, Schuurman, and Hawkins Hoffman, 2016). After considering specific management actions that would be appropriate in the different scenarios for each strategy, discussion groups decided which strategy was the preferred option in each scenario and evaluated similarities and differences across scenarios.
The group discussing cottonwood forests ascertained that accommodating change was the preferred option in the "severe, sustained drought" scenario because of the unlikelihood of cottonwoods surviving in hotter, drier conditions with little flooding. They anticipated that this approach would require an acceptance of grassland expansion into areas forested at the time of the workshop but would probably still require the control of exotic tree species such as Russian olive and tamarisk. In the scenario of least climate change, their preferred option was to direct change towards native forest types with a lower cottonwood component through hands-on management (create seedbeds with mechanical means, plant bur oak and box elder, control herbivores), although they realized that this would be expensive. Actions resisting changethose seeking to maintain cottonwood forest dynamics as close to historical conditions (before river flood control) as possible - were, somewhat paradoxically, preferred in the two wetter scenarios ("hot summer, soggy spring" and "hot flood 
seesaw") because these scenarios envisioned flooding more like what happened before dams controlled river flow. The main actions to achieve this strategy were minimizing bank stabilization and allowing river meandering. The discussion group realized, however, that this approach would likely be in direct conflict with the goal of preserving archeological sites along the river.

The group discussing archeological sites initially struggled with the resist, direct, or accommodate change framework because of the inherent stationarity of these resources. Unlike biological resources, archeological sites cannot adapt or evolve with changing conditions but only degrade at different rates. Ultimately, the group discussing this topic decided that a "resist change" strategy followed the existing approach of preserving archeological sites in place, a "direct change" strategy maximized the information extraction from sites through research archeology, and an "accommodate change" strategy was in effect salvage archeology - collecting available information as sites are exposed. They concluded that the last strategy was never a preferred option, that in situ preservation was always part of the preferred portfolio, and that research archeology would be a high priority in the two wetter (more flooding) scenarios. This group also realized the conflict between cottonwood forest and archeological sites but suggested that, especially in the two wetter scenarios, the research archeology approach could reduce this conflict by funding archeological research instead of bank stabilization. Continuation of the existing program for detailed monitoring of channel change and erosion along the Knife River (Sexton, 2012) will be important for quantifying future effects of climate change on both archaeological sites and cottonwood reproduction.

The group addressing vegetation components of the cultural landscape spoke exclusively about the topic as it applied to the NPS unit central to the focal area (Knife River Indian Villages National Historic Site, hereafter referred to as "the Historic Site"). This group also realized that the existing approach that Historic Site management uses is to resist change-attempt to maintain or restore native vegetation to its pre-European settlement state. This was a challenging discussion because, as the name "Knife River Indian Villages" suggests, the landscape was strongly shaped by the peoples that inhabited this site over thousands of years. The group consequently decided that the "direct change" strategy would aim to enhance populations of plant species important to the cultures associated with the location, thereby serving as a refuge for species that might disappear from the area without direct intervention. Accommodate change, in contrast, would let the vegetation change as climate conditions dictated while minimizing invasive species, particularly weeds considered noxious in adjacent agricultural areas. The group ascertained that in all but the "severe sustained drought" scenario, the resist change strategy would require some tweaks to existing management practices, such as adjusting the timing of prescribed fires from spring to fall, or putting more emphasis on mechanical removal of trees encroaching into grasslands. They thought that the resist change approach would not be feasible in much drier conditions. The group struggled with deciding on a preferred strategy for each scenario, however, because this preference depends on the goals of the Historic Site regarding the cultural landscape and vegetation, goals that have not been set and need to be decided with considerable consultation with Tribal partners.

Of those workshop participants that provided feedback after the workshop, all evaluated the workshop positively and expressed the intent or desire to use a scenario planning approach in other work that they do. Nearly all cited the chance to work with other agencies and the networking opportunities the workshop afforded as benefits, but some responses mentioned the difficulty of translating the results of the discussions into specific decisions at the Historic Site level, or applying them to different areas and management contexts, as shortfalls.

\subsubsection{Southwest South Dakota Focal Area Scenario Planning Workshop}

Participants in the orientation meeting for the southwest South Dakota focal area (which did not include the ecologically distinct Black Hills) expressed concerns about climate change effects on a wide range of topics. Extreme precipitation events and their erosion-related effects on paleontological resources and infrastructure were one concern. Drought was also a concern because of its effects on forage availability and longer-term grassland species composition and its carry-on effects on wildlife such as prairie dogs, black-footed ferrets, and bison (Amberg and others, 2012) and on domestic cattle leasing operations. Several other factors that affect the character and viability of grasslands and the viability of livestock and wildlife on this landscape were also discussed: invasive species, fire, and management actions (for example, stocking rates and the development of supplemental water sources). Participants identified three broad topics to address in the scenario planning workshop: (a) archaeological and paleontological resources; (b) grassland vegetation composition and productivity, bison and cattle grazing, and wildlife, particularly prairie dogs and black-footed ferrets; and (c) operations, including facilities and infrastructure.

As described above, these concerns drove our selection of four projections that formed the basis of the local climate scenarios used in the focal area scenario planning workshop. In this focal area, we paid special attention to four climate metrics: April-June precipitation, last spring freeze date, number of days with more than 1 inch of rainfall per year, and number of 5-day periods with more than 2.5 inches of rainfall per year. An analysis by Smart and others (2007) of long-term data from a location near the Park determined that the first two metrics were important drivers of annual production in grasslands like those in our focal area. A study of erosion rates in the Park indicated the importance of heavy rain events to this process that not only shapes the badlands features that give the Park its name but also determines the rate at which 
archeological and paleontological resources are exposed and deteriorated (Stetler, 2013).

In describing the four climate scenarios for this focal area, we incorporated lessons we learned from the central North Dakota workshop by putting even more emphasis on relating the climate scenarios to drought and deluge years within the memories of workshop participants (fig. 4). The "rather hot" scenario was chosen for its much warmer climate with little change in precipitation, whereas the "awfully dry" scenario emphasized a decrease in precipitation and, true to its name, was the driest of the 36 climate projections in the dataset from which we selected climate scenarios. The "wet in bursts" scenario was chosen to challenge managers with a substantial increase in precipitation and frequency of extreme precipitation events and increased interannual variability in precipitation. The hottest and wettest scenario was "the jungle;" it had a last spring freeze 15 days earlier than the historical average and had the greatest increase in spring precipitation of the 36 climate projections considered.

In small-group discussions (where the project team selected the participants in each group to deliberately include people with a range of interests and expertise) regarding the effects of each climate scenario, common topics included changes in agricultural practices, flooding impacts, vegetation productivity, invasive species, and maintenance needs. More intense storms, especially in the "rather hot," "wet in bursts," and "the jungle" scenarios, were envisioned to lead to greater erosion and impacts to archaeological resources, paleontological resources, and infrastructure. Increased poaching and vandalism of archeological and paleontological resources was highlighted in "wet in bursts." Changes in vegetation occurred in all scenarios and ranged from strong decreases in productivity and a shift towards shortgrass prairie (in "awfully dry") to increased productivity, tallgrass prairie expansion, exotic plant invasion, and woody encroachment (in "the jungle"). These changes in vegetation would affect grazers, including bison and prairie dogs, and the species dependent on them, such as black-footed ferrets. The "awfully dry" and "rather hot" scenarios envisioned increased public-private conflicts or pressure regarding wildlife and grazing leases, whereas a shift from ranching to row-crop agriculture was anticipated in the "wet in bursts" and "the jungle" scenarios. Warmer and wetter conditions were thought likely more conducive to plant, animal, and human diseases.

As in the central North Dakota focal area, the scenario planning workshop for southwestern South Dakota included small-group discussions examining the efficacy of different management strategies under the four climate scenarios. Participants self-selected which of these groups to participate in based on their expertise and interest. Given the difficulty of addressing static resources (for example, fossils, archeological sites) with the resist, accommodate, or direct change strategic framework used in the North Dakota workshop, we used a different set of adaptation strategies in our second workshop. In this framework (adapted from Stein and others, 2014), the "business as usual" strategy is used when existing goals and actions for a given issue are deemed appropriate and effective under the changing climate conditions within two timeframes defined for the discussion: through the year 2030 for shortterm and through the year 2050 for long-term. When existing goals are appropriate, but achieving them under new climate conditions requires revised management actions, the strategy is a "climate retrofit." A "climate rebuild" strategy is required when neither existing goals nor actions are considered tenable in the described future conditions and revisions to both are necessary for success. Given the larger number of participants in this workshop than in North Dakota, five focal concerns were addressed: archeological and paleontological resources; infrastructure, roads, and geohazards; native vegetation; bison; and the Federally endangered black-footed ferret.

The group addressing archeological and paleontological resources concluded that the existing goal of preserving and protecting these resources is achievable under all scenarios, but that major additional actions may be needed in some scenarios (table 3). Actions used to date include surveying, stabilizing, and salvaging exposed fossils or artifacts, protecting the resources from theft (law enforcement), and educating visitors about the resources found, most of which is done with in-house resources. The group concluded that the business as usual strategy was appropriate in the "awfully dry" scenario, because slightly fewer extreme precipitation events would potentially slightly reduce exposure of resources. The climate retrofit approach was deemed most appropriate in the other climate scenarios, as substantial increases in extreme precipitation events would require more salvage, survey, and protection actions than occur under conditions of the past two decades. Challenges foreseen in these scenarios included raising additional funds to achieve this higher activity level, logistical issues regarding the seasonal availability of students who are often engaged to do this work, and establishing a decision-making framework for prioritizing stabilization and excavation. Effective consultation with Tribal partners was seen as a necessity across all scenarios.

The group discussing infrastructure concluded that the goal of maintaining the safety and usability of existing infrastructure could be untenable in all but the "awfully dry" scenario, because rates of heavy precipitation events over the past half century already challenge existing capabilities. A main topic of discussion was the road travelled by nearly all visitors to the Park - a historic road built on the edge of and in places crossing a major geological feature known as "The Wall." The striking scenery associated with The Wall is caused by its rapid (in the geological sense) erosion rates. The group ascertained that new actions such as investing in in-house repair capabilities (equipment, staff) rather than contracting to address infrastructure failures more quickly could achieve the existing goal in the short term. However, they concluded that maintaining safety and accessibility of the Park in the long term in all but the "awfully dry" scenario will likely require realignment of existing roads, the development of a wholly new, sustainable, transportation system, or both. 

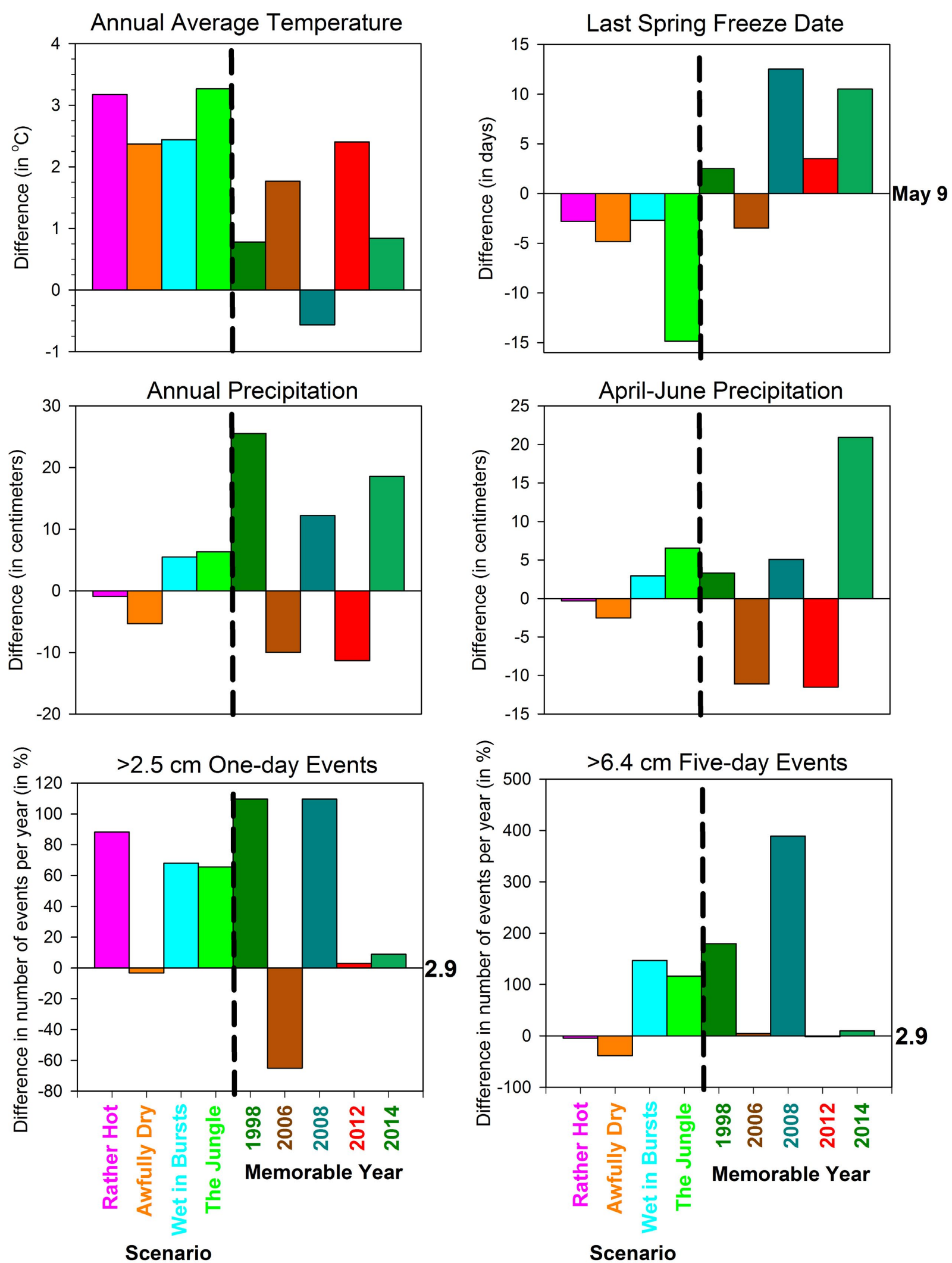

Figure 4. Differences in key climate metrics between southwest South Dakota focal area scenarios (2020-50 average) and their historical (1950-99) average, and between five single years and the historical (1956-99) average for the Interior, South Dakota, weather station. Details regarding the definitions and derivation of values for the climate metrics are in Fisichelli and others (2016b); ${ }^{\circ} \mathrm{C}$, degrees Celsius; \%, percent; cm, centimeter. 
Table 3. Workgroup assessment of the achievability of existing goals compared to needed revisions by 2050 for five resources.

[The adaptation responses shown in the table below include "business as usual" (existing goals and actions are achievable), "climate retrofit" (existing goals are achievable with revised actions), and "climate rebuild" (revised goals and actions are necessary)]

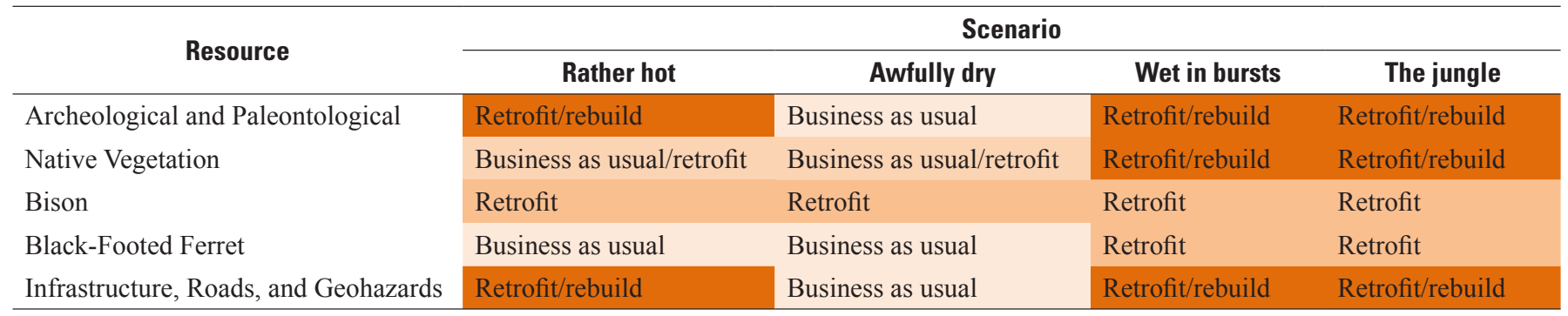

An important revelation at the beginning of the discussion regarding native vegetation was that the Park has no stated goal for this resource. In contrast, the neighboring Grassland has a specific goal of maintaining stated percentages of its land in various plant communities related to the "historical climax plant community." The group applied the latter goal to both entities for the purpose of the workshop discussion. Management actions used by both the Park and the Grassland include prescribed fire, biological and chemical control of invasive plants, and grazing by bison or cattle. The details of each management action differ greatly between the two agencies, however; the Grassland has much greater control of grazing than the Park does, and the Park invests far more in chemical control of invasives than the Grassland does. The group thought that the existing goal is achievable in the short-term (2030) with management actions already in use under the drier scenarios ("rather hot" and "awfully dry"), but it would not be achievable with existing management actions in the wetter scenarios ("wet in bursts" and "the jungle") because of expected increases in vegetation productivity, woody encroachment, and invasive plant abundance and diversity. They concluded that the goal would not be tenable in the long term in any scenario without greater flexibility in management actions than existed at the time of the discussion. They envisioned needing greater ability to adjust grazing leases in the Grassland and more management control of when and where bison graze on the Park through fencing, water and mineral lures, and targeted prescribed fire-actions that were not available at the time of the discussion. The group realized that across all scenarios, trying to maintain plant communities suited to a historical climate may be a losing battle and that adjustment of goals would likely be necessary in the long term. They also discussed the higher-level decision making that would be needed to achieve greater management flexibility, such as revision of existing grazing lease policy on the Grassland, and the granting of exceptions in designated Wilderness within the Park.

Bison are a major resource management emphasis in this region because of their status as native wildlife and charismatic megafauna in the Park and their cultural importance to local tribes. Existing bison management goals include maintaining herd health, promoting genetic diversity within and across herds (which requires maintaining a minimum herd size), establishing herds on Tribal lands for production and cultural use, and ensuring rangeland (vegetation) health. The primary management tool used to achieve these goals at the Park is periodic culling of the herd, in which bison are rounded up into a static facility using the water in this facility as a lure, and excess animals are shipped to receiving entities, including tribes. More flexibility in round-up methods (that is, more use of motorized vehicles) exists outside of the Park. The group discussing bison management concluded that the animals themselves tolerate a wide range of climatic conditions and are quite adaptable but that management is often not flexible enough to match the dynamism of the system and adaptability of the bison. The group assumed that existing Park goals for bison herd size would need to be adjusted downward in the two drier scenarios and that achieving this would require more frequent round-ups (and the funding to do them) than existing practice. They also discussed the need for stronger fences and more water developments in these scenarios, because bison now occasionally break through existing fencing in drought years in search of water. The group concluded that, in the wetter scenarios, herd size and genetic diversity goals would be achievable (though Park round-ups could become more challenging) but that achieving herd health goals may require more monitoring and development of new vaccines against emerging diseases. The group expressed the need, regardless of future climate conditions, for an inclusive (U.S. agencies, multiple tribes) regional bison plan that might include new actions such as a bull exchange program or revised culling strategies based on the most up-to-date science.

Management goals and actions regarding the black-footed ferret discussed in this workshop focused on prairie dogs, its primary prey. The existing goal identified for the workshop exercise was to expand the extent of prairie dog colonies. The management action used since the outbreak of plague in the vicinity of The Park is applying a flea-control insecticide to prairie dog holes to prevent prairie dog mortality through disease (sylvatic plague). The small discussion group concluded 
that the existing goal is likely achievable in the short and long term in the "rather hot" and "awfully dry" scenarios because the shorter vegetation associated with dry conditions favor expansion of prairie dog towns. In these scenarios, however, reduced forage for cattle in the Grassland may increase pressure from grazing permittees to reduce the extent of prairie dog towns; overcoming this pressure would require expanded partnerships and strengthened relationships among stakeholders. In contrast, the workgroup decided the existing goal would be unachievable across all periods in the wetter scenarios ("wet in bursts" and "the jungle") because of changes in vegetation (taller vegetation and woody encroachment). The group envisioned a revised goal of maintaining the existing extent of prairie dogs, and a new management action of higher cattle stocking rates to achieve this goal, in these scenarios.

Based on participant feedback from the North Dakota workshop and the broader experience of the project team with scenario planning, we included an additional exercise at the end of this workshop to illustrate how managers might operationalize information generated during workshop discussions. In this exercise, resource workgroups chose an action different from existing practice, identified triggers that would indicate when the action is applicable, and created a timeline of steps needed to implement the action; for example, the black-footed ferret group identified increased grazing and prescribed fire as their action and a contraction of the area occupied by prairie dogs of more than 20 percent in two consecutive surveys as the trigger for when this action would be applicable. They imagined that the first steps to implement the actions would be speaking with grazing permittees and beginning the process of an Environmental Impact Statement or Environmental Assessment. These steps would be necessary to achieve the easier step-higher grazing intensity. If this intervention failed to achieve its goal, then planning for prescribed fire would be started, possibly including town hall meetings to address public concerns regarding prescribed fire.

As with the North Dakota workshop, feedback on the South Dakota workshop was positive, though some participants stated that learning the process, rather than the actual results of the process, was more useful for their work. This may be because the South Dakota workshop included a broader array of participants, and covered a broader range of resource management issues over a larger area, than the North Dakota workshop did. This diversity was almost universally cited as a positive aspect of the workshop, though. Project staff witnessed genuine revelations in some small group discussions, particularly the planting of the idea that the conservative (small) bison herd size at the Park and assumed consequent light grazing rates may be contributing to the unacceptably high abundance of invasive annual grasses within the Park. This revelation came about because the workshop brought together managers with different expertise and experience from different agencies with different management goals and approaches. Our quantitative modeling of vegetation dynamics explored this idea in much more detail.

\subsubsection{Quantitative Modeling of Grassland Vegetation Dynamics in the Southwest South Dakota Focal Area}

This simulation modeling effort provided several insights valuable to both managers and scientists regarding (a) biomass availability for grazers during dry periods, (b) tradeoffs between biomass security and vegetation composition, (c) the contribution to important ecosystem components of climate relative to management, and (d) the state of knowledge regarding the response of these grasslands to various management practices.

Discussions in the scenario planning workshop reasonably assumed that plant production would be lower in the "awfully dry" and "rather hot" climate scenarios than in the "wet in bursts" and "the jungle" scenarios and that the former scenarios would require that managers reduce their herd sizes or grazing levels, compared to existing practice, to maintain vegetation and grazer health. During the management response workshop, managers and scientists saw that the quantitative modeling strongly supported the first assumption (fig. 5), but the model results did not always support the latter assumption. Specifically, when herd size or grazing consumption was relatively conservative, as represented by all simulated management alternatives in the Park and the Reservation compared to the Grassland, live biomass always remained at the end of the growing season (that is, peak live biomass) regardless of climate scenario or management alternative (fig. 6, middle and bottom panels), suggesting that the animals would always have forage available even in a drier climate. The sensitivity analysis also yielded a negative association between bison herd size and undesired vegetation states, indicating that too little grazing, even in drier climates, would lead to a decline in vegetation health. On the other hand, more aggressive grazing consumption, as represented by Grassland management alternatives, did result in unacceptably low standing biomass in much of the "awfully dry" climate scenario, and the highest grazing level we simulated ("planning for good conditions" in the Grassland) even resulted in running out of forage altogether (fig. 6, top panels).

The simulation modeling thus provided tangible evaluation - and general confirmation - of the idea planted during the January workshop that the conservative herd size at the Park has contributed to invasion by exotic cool-season grasses, but allayed manager fears about running out of grass in drier climates. Discussion during the management response workshop pointed out, though, that other factors - especially water availability and logistical constraints on handling more animals - may limit the number of animals more than plant production, especially at the Park. These factors were not accounted for in the simulation model.

Providing this better understanding of the magnitude of ecosystem changes plausible in different (still plausible) climate change scenarios is, we believe, one of the most important contributions of quantitative simulation modeling to climate change scenario planning, an opinion supported 


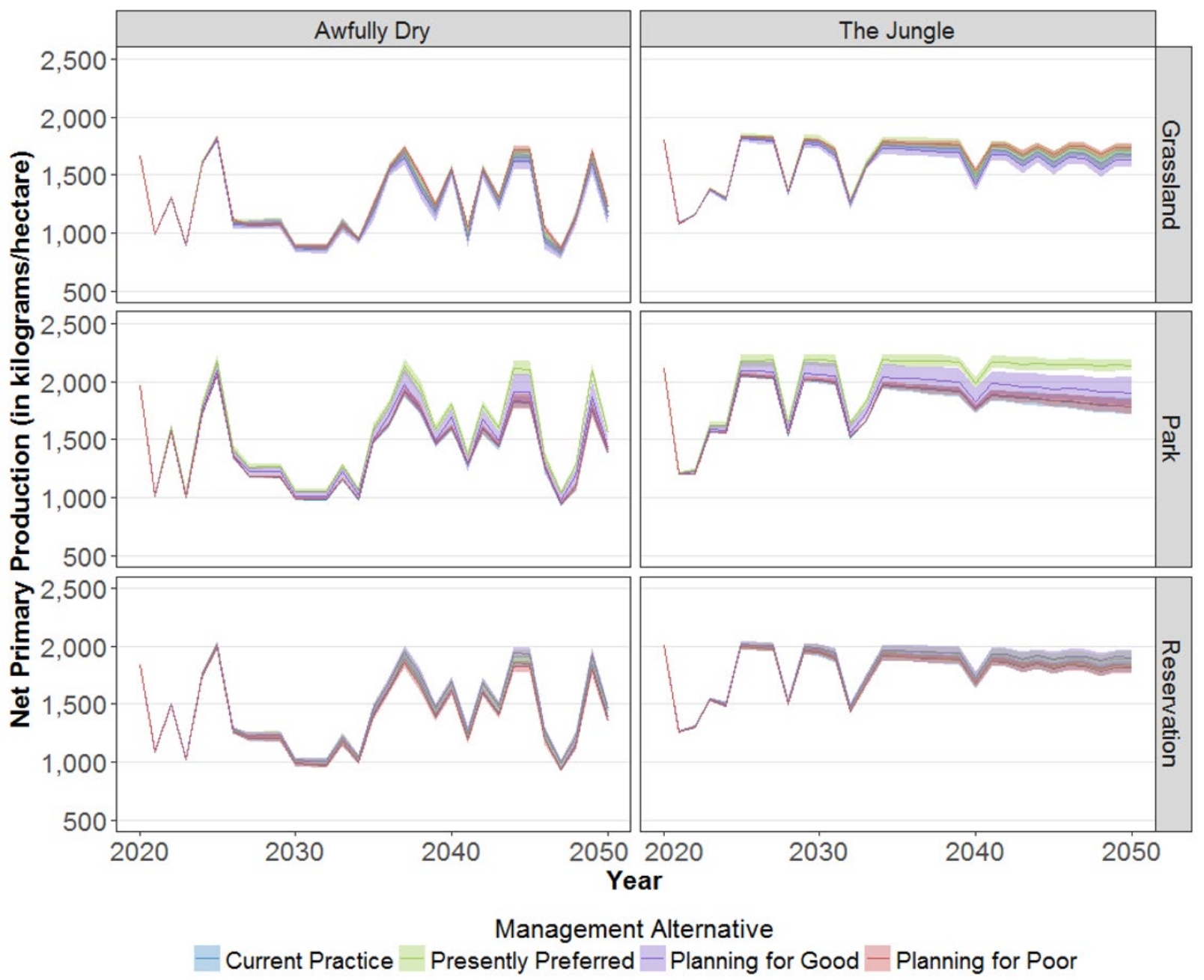

Figure 5. Simulated net primary production for each management jurisdiction (Grassland, Buffalo Gap National Grassland; Park, Badlands National Park; Reservation, Pine Ridge Reservation) under two climate scenarios (columns) and four management alternatives (colored lines). Lines represent the means of 100 Monte Carlo simulations and shaded regions represent the 95 th percentile range.

by our work with other scenario planning exercises (Symstad and others, 2017). This understanding extends to recognizing the relative size of effects of climate compared to management on ecosystem responses of concern. In this region, strong interannual fluctuations in precipitation are reflected in strong fluctuations in plant production, so much so that interannual production fluctuations were of similar magnitude to production differences among climate scenarios, and they dwarfed the effects of management on production, in our simulations (fig. 5). However, management effects and their often subtle interactions with long-term climate conditions are often more noticeable on a decadal or longer timeframe, as our model revealed in the proportion of the landscape occupied by various vegetation states (fig. 7). Teasing out these interactions during the scenario planning workshop was not possible.
Managers expressed their appreciation for the implications drawn from the results of the simulation modeling, but they also understood the limitations of the model. Foremost among these were the fact that the conceptual models on which our simulations were based are in a provisional stage (untested by experiments or long-term monitoring) and the related lack of empirical data on which to base the state transition probabilities, for which we used expert elicitation. In addition, our fairly simple incorporation of climate effects on vegetation production and composition may have resulted in a stronger effect of management than climate on vegetation composition, and considerably more work needs to be done to better evaluate the relative size of their contributions in northern Great Plains grasslands (for example, Haferkamp and others, 1993; Collins and others, 2012; Koerner and Collins, 


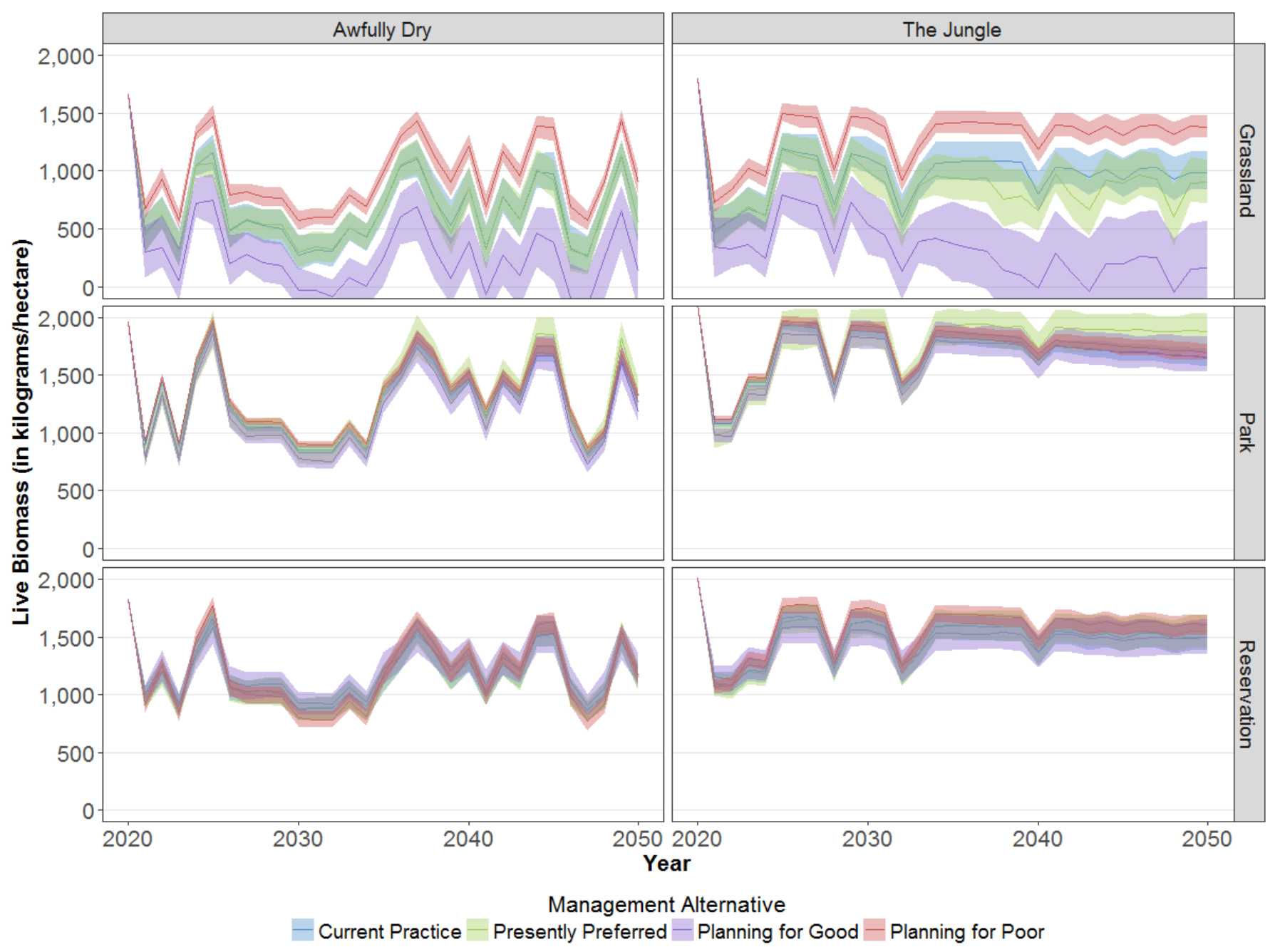

Figure 6. Simulated live biomass for each management jurisdiction (Grassland, Buffalo Gap National Grassland; Park, Badlands National Park; Reservation, Pine Ridge Reservation) under two climate scenarios (columns) and four management alternatives (colored lines). Lines represent the means of 100 Monte Carlo simulations and shaded regions represent the 95th percentile range.

2014; Jonas and others, 2015). Management decisions often cannot wait for all the science to be completed, however, and Park managers, especially, envisioned using the results of the simulation modeling as evidence to justify funding and policies that would allow for a more active prescribed fire program and greater flexibility in managing bison numbers.

\subsection{Conclusions and Recommendations}

\subsubsection{Incorporating More Quantitative Methods into NPS Scenario Planning Efforts}

One of the motivations for this project was the desire by the NPS to make their scenario planning process more quantitative. This project has provided us with the knowledge and experience to build a framework for doing so, and we have described this framework in another publication (Symstad and others, 2017). This framework is a modest modification to the process we followed in this project, incorporating factors that, in hindsight, we would have done differently (for example, a model sensitivity analysis earlier in the process).

Increased quantification is useful in several stages of scenario planning. The most straightforward is at the stage of producing local climate scenarios. Having specific values for meaningful parameters in each scenario makes it possible to relate each scenario to events that participants can identify with. After realizing that our originally envisioned "scaling down" approach was not optimal, we sought a means to automate the acquisition and summary of climate projection data to make the process of selecting and documenting 


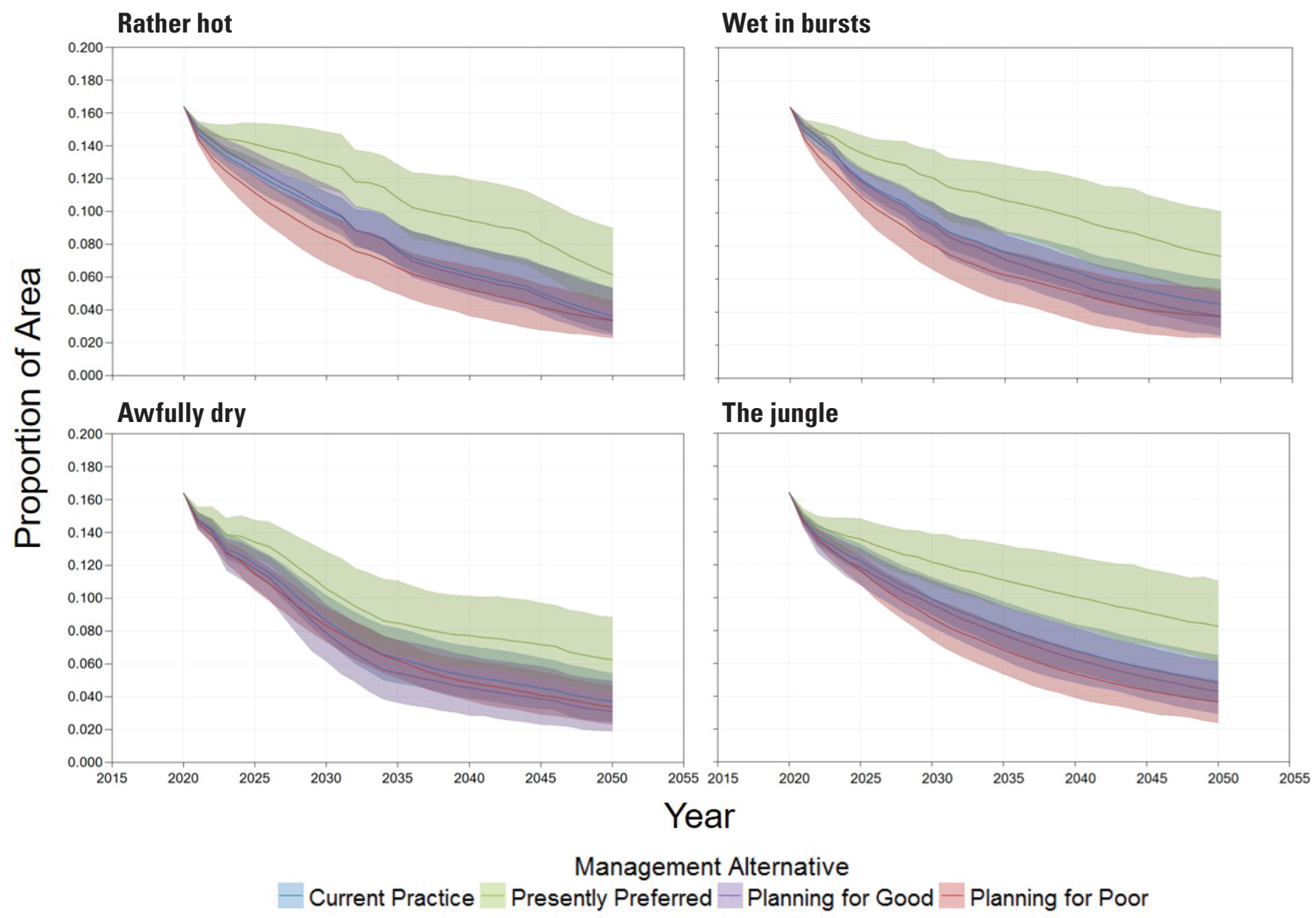

Figure 7. Example of how climate and management interact over the long term (2020-50). Simulated proportion of Buffalo Gap National Grassland landscape occupied by the western wheatgrass/needle-and-thread state class through time in four climate scenarios (panels) and four management alternatives (colored lines). Lines represent the means of 100 Monte Carlo simulations and shaded regions represent the 95 th percentile range.

climate scenarios for NPS climate change scenario planning workshops more efficient and consistent than the procedure we improvised for this situation. We partially completed this quest by funding staff of the USGS South Dakota Water Science Center to write R scripts for acquiring climate projection data from online climate data portals and calculating a suite of climate metrics for each projection. Further work needs to be done, though, to complete this new direction. This work and our experiences compiling climate summaries for this project are informing the continued efforts by the NC CSC, in collaboration with NPS and other entities that have begun similar efforts, to develop a more comprehensive climate summaries tool.

Less straightforward is the degree of effort to put into quantitative modeling of ecosystem or resource response to climate change and management. Our experience with the two different focal areas illustrates a spectrum of possibilities.
Quantifying some responses for important issues, like flooding frequency of a river, may simply require finding already existing simulation model output or, as for the Knife River, a specialist knowledgeable enough to use existing output as a proxy for the exact response desired. In our proposal stage, we anticipated using results from a dynamic vegetation model from an earlier project as part of our quantification of ecosystem responses in this project. We ended up not using these, however, because the climate scenarios behind the simulations from the earlier project were quite different from those used in this project. The simulation model used in the earlier project also did not address vegetation composition or invasive species control and lacked flexibility in applying different grazing regimes. This prompted us to build a new model that, although it used existing software and was therefore much easier than producing original code, still took considerably more effort than we anticipated at the beginning of the project; thus, early 
determination of the ecosystem response variables that would most benefit from quantitative modeling, and what type of modeling is required, in the planning process is paramount for efficient use of time and financial resources. A formal structured decision-making process may even be warranted for making this determination in that it would clearly identify the value of information to be gained by different options.

\subsubsection{Things We May Have Done Differently and Recommended Next Steps}

Although our management partners (stakeholders) and we ourselves were mostly satisfied with the outcome of the project, there are four things that we would do differently:

- Achieve better representation of Tribal stakeholders in scenario planning workshops and relevant quantitative modeling. We made several attempts to include the appropriate people but, ultimately, were only able to engage one Tribal stakeholder at the North Dakota workshop and two Tribal stakeholders at the South Dakota workshop.

- Make better use of the NC CSC in-house expertise, especially the climate Foundational Science Area. We did not understand the role of this expertise at the beginning of the project.

- Allocate a longer project period to complete end-userfriendly products.

- Connect the scenario planning and simulation modeling work to a definite decision or planning document that stakeholders are anticipating, and ensure that there is adequate time before this decision needs to be made or the document completed for the project to produce the needed information.

Based on these and other items mentioned throughout this report, we recommend the following next steps:

- NC CSC and future solicited projects.-Allow for additional time to engage managers in the process, and to expand the group of local experts by engaging local resource users who could draw on traditional ecological knowledge and practice-based knowledge to assist with model coproduction and improve model relevance to local communities.

- NPS Climate Change Response Program/NC CSC.Complete the work we began to produce a flexible yet repeatable method for selecting and producing quantitative climate scenarios.

- NPS Climate Change Response Program.-Determine a method for deciding where greater quantification of the scenario planning process is most beneficial and cost effective.
- Project Team.-Consult with project stakeholders (actual participants and their successors and supervisors) to determine the shape and form of one or more management-relevant end products that document the voluminous and multifaceted results of the modeling so that the results will be used in future planning efforts. We have obtained funds from NC CSC to do this.

\subsection{Outreach and Products}

\subsubsection{Peer-Reviewed Publications and Reports}

Fisichelli, Nicholas, Schuurman, Gregor, Symstad, Amy, Ray, Andrea, Friedman, Jonathan, Miller, B.W., and Rowland, Erika, 2016a, Resource management and operations in central North Dakota: Climate change scenario planning workshop summary November 12-13, 2015, Bismarck, ND: Fort Collins, Colo., National Park Service, Natural Resource Report NPS/NRSS/NRR—2016/1262, 44 p.

Fisichelli, Nicholas, Schuurman, Gregor, Symstad, Amy, Ray, Andrea, Miller, B.W., Cross, Molly, and Rowland, Erika, 2016b, Resource management and operations in southwest South Dakota: Climate change scenario planning workshop summary January 20-21, 2016, Rapid City, SD: Fort Collins, Colo., National Park Service, Natural Resource Report NPS/NRSS/NRR—2016/1289, 61 p.

Friedman, J.M., and Griffin, E.R., 2017, Management of plains cottonwood at Theodore Roosevelt National Park, North Dakota: Fort Collins, Colo., National Park Service Natural Resource Report NPS/THRO/NRR—2017/1395, $31 \mathrm{p}$.

Friedman, J.M., Ankney, F.R., and Wolf, M., 2017, Age and growth of cottonwood trees along the Missouri River: Prairie Naturalist, in review.

Griffin, E.R., and Friedman, J.M., 2017, Decreased runoff response to precipitation, Little Missouri River Basin, northern Great Plains, USA: Journal of the American Water Resources Association, v. 53, no. 3, p. 576-592, https://doi.org/10.1111/1752-1688.12517.

Miller, B.W., Schuurman, G.W., Symstad, A.J., and Fisichelli, N.A., 2017, Embracing complexity and uncertainty: Merging qualitative and quantitative tools to inform natural areas management under climate change: Park Science, in preparation.

Miller, B.W., Symstad, A.J., Fird, Leondardo, Fisichelli, N.A., and Schuurman, G.W., in press, Co-producing simulation models to inform resource management: A case study from southwest South Dakota: Ecosphere. 
Symstad, A.J., Fisichelli, N.A., Miller, B.W., Rowland, Erika, and Schuurman, G.W., 2017, Multiple methods for multiple futures: Integrating qualitative scenario planning and quantitative simulation modeling for natural resource decision making: Climate Risk Management, v. 17, p. 78-91, https://doi.org/10.1016/j.crm.2017.07.002.

\subsubsection{USGS Data Release}

Miller, B.W., Symstad, A.J., Frid, Leonardo, Fisichelli, Nicholas, and Schuurman, G.W., 2017, State-and-transition simulation model of rangeland vegetation in southwest South Dakota (1969-2050): U.S. Geological Survey data release, at https://doi.org/10.5066/F7T1524X.

\subsubsection{Presentations at Professional Meetings}

Miller, B.W., and Morisette, J.T., 2017, State-and-transition simulation modeling: A tool for assessing the interacting effects of climate, ecological processes, and management on wildlife habitat: Fort Collins, Colo., The Colorado Chapter of the Wildlife Society Annual Meeting.

Miller, B.W., and Morisette, J.T., 2017, Simulating the effects of climate change and resource management on ecosystems: Case studies from forest and rangeland systems using stateand-transition simulation modeling: Jackson, Wyo., 13th Biennial Scientific Conference of the Greater Yellowstone Ecosystem.

Morisette, J.T., Miller, B.W., and Jarnevich, C.S., 2016, Using state and transition simulation models to consider complex forcing in ecological analysis to support land management decisions: Fort Lauderdale, Fla., Ecological Society of America.

Ray, A.J., Symstad, A.J., Miller, B.W., Fisichelli, N.A., Schuurman, G.W., Friedman, J.M., and Rowland, Erika, 2015, Scaling climate change adaptation in the northern Great Plains through regional climate summaries and local qualitative-quantitative scenario planning workshops: San Francisco, Calif., American Geophysical Union.

Symstad, A.J., Miller, B.W., Frid, Leonardo, Fisichelli, N.A., and Schuurman, G.W., 2017, Range management and climate adaptation: Quantitatively deciding how to let the chips fall: St. George, Utah, Society for Range Management.

Symstad, A.J., Miller, B.W., Frid, Leonardo, Fisichelli, N.A., and Schuurman, G.W., 2017, A model for exploring grassland management in alternative climate scenarios: Rapid City, S. Dak., Black Hills Area Botany and Ecology Workshop.

\subsubsection{Invited Talks, Lectures, and Webinars}

Miller, B.W., 2016, Leveraging the strengths of multiple methods through simulation modeling: National Climate Change and Wildlife Science Center, All Climate Science Center Webinar, October 12, 2016.

Miller, B.W., 2016, Scenario planning: Integrated Ecosystem Management (NR 420), Warner College of Natural Resources, Colorado State University, October 25, 2016.

Miller, B.W., 2016, Scenario planning: Integrated Ecosystem Management (NR 420), Warner College of Natural Resources, Colorado State University. March 29, 2016.

Symstad, A.J., Fisichelli, N.A., and Miller, B.W., 2016, Quantitative modeling and participatory scenario planning: Complementary tools for climate change adaptation: North Central Climate Science Center, Adaptation Working Group Webinar, September 13, 2016.

\section{References Cited}

Amberg, Shannon, Kilkus, Kathy, Gardner, Sarah, Gross, J.E., Wood, Melanie, and Drazkowski, Barry, 2012, Badlands National Park - Climate change vulnerability assessment: Fort Collins, Colo., National Park Service, Natural Resource Report NPS/BADL/NRR—2012/505, 340 p.

Apex Resource Management Solutions, 2017, ST-Sim state-and-transition simulation model software. Retrieved from http://www.apexrms.com/state-and-transition-simulation-models/.

Collins, S.L., Koerner, S.E., Plaut, J.A., Okie, J.G., Brese, Daniel, Calabrese, L.B., Carvajal, Alejandra, Evansen, R.J., and Nonaka, Etsuko, 2012, Stability of tallgrass prairie during a 19 -year increase in growing season precipitation: Functional Ecology, v. 26, no. 6, p. 1450-1459.

Fisichelli, N.A., Schuurman, G.W., and Hawkins Hoffman, Cat., 2016, Is 'resilience' maladaptive? Towards an accurate lexicon for climate change adaptation: Environmental Management, v. 57, no. 4, p. 753-758.

Fisichelli, Nicholas, Schuurman, Gregor, Symstad, Amy, Ray, Andrea, Friedman, Jonathan, Miller, B.W., and Rowland, Erika, 2016a, Resource management and operations in central North Dakota: Climate change scenario planning workshop summary November 12-13, 2015, Bismarck, ND: Fort Collins, Colo., National Park Service, Natural Resource Report NPS/NRSS/NRR—2016/1262, 44 p. 
Fisichelli, Nicholas, Schuurman, Gregor, Symstad, Amy, Ray, Andrea, Miller, B.W., Cross, Molly, and Rowland, Erika, 2016b, Resource management and operations in southwest South Dakota: Climate change scenario planning workshop summary January 20-21, 2016, Rapid City, SD: Fort Collins, Colo., National Park Service, Natural Resource Report NPS/NRSS/NRR—2016/1289, $61 \mathrm{p}$.

Haferkamp, M.R., Volesky, J.D., Borman, M.M., Heitschmidt, R.K., and Currie, P.O., 1993, Effects of mechanical treatments and climatic factors on the productivity of Northern Great Plains rangelands: Journal of Range Management, v. 46 , no. 4 , p. $346-350$.

Jonas, J.L., Buhl, D.A., and Symstad, A.J., 2015, Impacts of weather on long-term patterns of plant richness and diversity vary with location and management: Ecology, v. 96, no. 9, p. 2417-2432.

Koerner, S.E., and Collins, S.L., 2014, Interactive effects of grazing, drought, and fire on grassland plant communities in North America and South Africa: Ecology, v. 95, no. 1, p. $98-109$.

Kunkel, K.E., Stevens, L.E., Stevens, S.E., Sun, Liquiang, Janssen, Emily, Wuebbles, Donald, Kruk, M.C., Thomas, D.P., Shulski, M.D., Umphlett, N.A., Hubbard, K.G., Robbins, Kevin, Romolo, Luigi, Akyuz, Adnan, Pathak, T.B., Bergantino, T.R., and Dobson, J.G., 2013, Regional climate trends and scenarios for the U.S. National Climate Assessment-Part 4. Climate of the U.S. Great Plains: Washington, D.C., National Oceanic and Atmospheric Administration, NOAA Technical Report NESDIS 142-4.

Miller, B.W., Symstad, A.J., Frid, Leonardo, Fisichelli, Nicholas, and Schuurman, G.W., 2017, State-and-transition simulation model of rangeland vegetation in southwest South Dakota (1969-2050): U.S. Geological Survey data release, at https://doi.org/10.5066/F7T1524X.

Miller, B.W., Symstad, A.J., Frid, Leonardo, Fisichelli, N.A., and Schuurman, G.W., in press, Co-producing simulation models to inform resource management-A case study from southwest South Dakota: Ecosphere.

National Park Service, 2013, Using scenarios to explore climate change: A handbook for practitioners: Fort Collins, Colo., U.S. Department of the Interior, National Park Service Climate Change Response Program, 57 p.
Reclamation, 2013, Downscaled CMIP3 and CMIP5 climate and hydrology projections archive: Denver, Colo., U.S. Department of the Interior, Bureau of Reclamation, Technical Services Center, accessed October 22, 2015, at https://gdo-dcp.ucllnl.org/downscaled_cmip_projections/.

Sexton, C.L., 2012, Movements of the Knife River within Knife River Indian Villages National Historic Site; 1965 to 2011: Medora, N. Dak., Theodore Roosevelt National Park Geospatial Science Laboratory, 38 p.

Smart, A.J., Dunn, B.H., Johnson, P.S., Xu, Lan, and Gates, R.N., 2007, Using weather data to explain herbage yield on three Great Plains plant communities: Rangeland Ecology \& Management, v. 60, no. 2, p. 146-153.

Stein, B.A., Glick, Patty, Edelson, N.A., and Staudt, Amanda, 2014, Climate-smart conservation: Putting adaptation principles into practice: Washington, D.C., National Wildlife Federation, 262 p. [Also available at https://www.nwf.org/ / media/PDFs/Global-Warming/Climate-Smart-Conservation/ NWF-Climate-Smart-Conservation_5-08-14.pdf.]

Stetler, L., 2013, Determining erosion rates at select fossil sites to develop a paleontological monitoring program: Final report to the National Park Service Badlands National Park Resource Management Office: Rapid City, S. Dak., South Dakota School of Mines and Technology, FRR063014 (updated 093014), $222 \mathrm{p}$.

Sun, Liquang, Kunkel, K.E., Stevens, L.E., Buddenberg, Andrew, Dobson, J.G., and Easterling, D.R., 2015, Regional surface climate conditions in CMIP3 and CMIP5 for the United States: Differences, similarities, and implications for the U.S. National Climate Assessment: Washington, D.C., National Oceanic and Atmospheric Administration, NOAA Technical Report NESDIS 144, $111 \mathrm{p}$.

Symstad, A.J., Fisichelli, N.A., Miller, B.W., Rowland, Erika, and Schuurman, G.W., 2017, Multiple methods for multiple futures: Integrating qualitative scenario planning and quantitative simulation modeling for natural resource decision making: Climate Risk Management, v. 17, p. 78-91, https://doi.org/10.1016/j.crm.2017.07.002. 
For more information concerning this publication, contact:

Director, USGS Northern Prairie Wildlife Research Center 8711 37th Street Southeast

Jamestown, North Dakota 58401

(701) 253-5500

Or visit the Northern Prairie Wildlife Research Center website at:

https://www.npwrc.usgs.gov/

Publishing support provided by the Rolla and Pembroke Publishing Service Centers 


\section{$\frac{\mathbb{2}}{3}$}

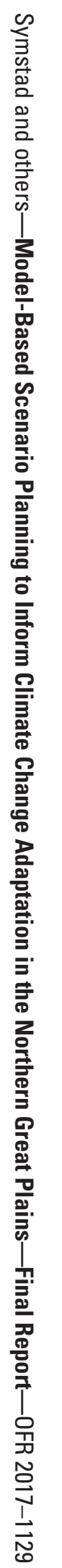

